\title{
Features in Phonological Theory
}

\author{
Marcus Kracht \\ II.Mathematisches Institut \\ Freie Universität Berlin \\ Arnimallee 3 \\ D - 14195 Berlin \\ E-mail: krachtemath.fu-berlin.de
}

\begin{abstract}
Features are central in phonological theory. They come in different varieties. Using the methods of [263] we shall analyse a few conditions on phonological structures. This will elucidate the tradeoff between features on the one hand (and structure) and principles on the other. Without making any claims as to which method is superior, we shall simply outline what choices one has in describing the facts one or the other way.
\end{abstract}

\section{Introduction}

There are two seemingly exclusive views on syntactic structures: the descriptive and the derivational view. A descriptivist is interested in defining proper representations and describing the class of representations that occur in language (or in a specific language). A derivationalist wants to create a theory on how to make structures or representations. Work by James Rogers (see [395], [396]) and by the present author in [261] and [263] emphasizes that there is no reason to believe that these views are

Received: February 22nd, 2001;

In revised version: July $23 \mathrm{rd}, 2001$;

Accepted by the editors: August 15 th, 2001.

2000 Mathematics Subject Classification. 91F20 03-99. 
exclusive. Moreover, methods are provided to translate between representational and derivational theories. Though the scope of these methods is somewhat limited (they basically deal with context free grammars), more recent work by the present author ([266, 264, 265]) shows that derivational theories can be recast in fully representational terms in a nontrivial way. Nevertheless, as much as these results show that there are translations between these approaches, the distinction between a representational and a derivational setup is far from negligeable. In particular, the explanatory character and scope of these approaches is quite different. The present paper tries to shed some light on this problem area. We shall focus here on the nature of phonological representations, in particular features. The reason for doing so is twofold. First, features are central in phonology, and second, the coding of phonological constraints in the sense of Kracht [261] leads to the introduction of features. These features are necessarily nonphonemic, that is, they do not serve to distinguish phonemes. As it turns out, the ones we have seen so far are eliminable in the sense of [263], since the language of correct phonological strings is regular (at least in all languages that we know of) and the distribution of these features is definable from the phonemic features. Two particular examples shall be studied: one is the set of features that regulate the structure of the syllable, which we call positional features. The other set of features is necessitated by vowel harmony. They constitute what we call memory features.

This paper is structured as follows. In Section 2 we shall introduce some logic (in particular propositional dynamic logic with converse) and prove some results on the definability of languages. In Section 3 we shall discuss the process of phonemicization and its relation to the Bethproperty in modal logic. Section 4 discusses the syllable structure and shows that syllable structure cannot be reduced to collocation restrictions (= sandhi). Section 5 introduces the phenomenon of vowel harmony and 6 discusses possible solutions within Autosegmental Phonology. Finally, in Section 7 we shall discuss the necessity of introducing morphophonemic features.

I wish to thank András Kornai for discussing this paper with me. Needless to say that I take full responsibility for all omissions and errors. 


\section{Preliminaries}

The natural number $n$ is identified here with the set $\{0,1, \ldots, n-1\}$. An $A$-string of length $n$ is a function $f: n \rightarrow A$. We use $\boldsymbol{x}, \boldsymbol{y}$ etc as metavariables for strings. Given two strings $\boldsymbol{x}: m \rightarrow A$ and $\boldsymbol{y}: n \rightarrow A$, the concatenation $\boldsymbol{x} \cdot \boldsymbol{y}$ is defined as follows. Its domain is the set $m+n$ and

$$
\boldsymbol{x} \cdot \boldsymbol{y}(i):= \begin{cases}\boldsymbol{x}(i), & \text { if } i<m, \\ \boldsymbol{y}(i-m), & \text { otherwise. }\end{cases}
$$

We write $\varepsilon$ for the unique $A$-string of length $0 . A^{*}$ is the set of all $A$ strings.

A language over $A$ is a subset of $A^{*}$. Regular terms over $A$ are terms produced from the symbols of $A$ and $\varnothing, \varepsilon$, by means of the connectives * (Kleene Star), $\cup$ (union) and · (complex product, often omitted).

$$
\begin{array}{lll}
E(\varnothing) & :=\varnothing, & \\
E(\varepsilon) & :=\{\varepsilon\}, & \\
E(a) & :=\{a\}, & \\
E(T \cup U) & :=E(T) \cup E(U), & \\
E(T \cdot U) & :=\{\boldsymbol{x} \cdot \boldsymbol{y}: \boldsymbol{x} \in E(T), \boldsymbol{y} \in E(U)\}, & \\
E\left(T^{*}\right) & :=\bigcup_{n \in \omega} E(T)^{n} .
\end{array}
$$

(Here, $E(T)^{n}=E(T) \cdot E(T) \cdot \ldots \cdot E(T)$, the $n$-fold product.) Given a regular term $T, E(T)$ is a set, the set of strings of $T$. A language is regular if it has the form $E(T)$ for some regular term $T$. It is easy to see that $\varnothing$ is needed only to define the empty language. Similarly, if $L$ is regular and contains $\varepsilon$, then $L-\{\varepsilon\}$ is regular and can be defined without the help of $\varepsilon$. Given $v: A \rightarrow B^{*}$, we write $\bar{v}$ for the unique homomorphism $A^{*} \rightarrow B^{*}$ extending $v$. That is to say, $\bar{v}$ satisfies:

1. $\bar{v}(\varepsilon)=\varepsilon$.

2. $\bar{v}(a)=v(a), \quad a \in A$.

3. $\bar{v}(\boldsymbol{x} \cdot \boldsymbol{y})=\bar{v}(\boldsymbol{x}) \cdot \bar{v}(\boldsymbol{y})$.

This map always exists and is unique. It is known that regular languages are exactly the languages that are recognizable by a finite state automaton. Moreover, there are effective methods to create an automaton from a regular term $T$ recognizing the language $E(T)$, and to compute from an automaton $\mathfrak{A}$ a term $T$ such that $L(\mathfrak{A})=E(T)$. The third way to describe regular language is the axiomatic approach. Büchi has shown that 
a language is regular iff the corresponding class of model structures is MSO-axiomatizable. Here, MSO is the language of monadic second order predicate logic with a single binary relation constant (for adjacency) and unary constants for all letters. There is a logic that is powerful enough to axiomatize exactly the regular languages, and moreover it is expressibly weaker than MSO.

This logic is called Propositional Dynamic Logic with Converse ( $\left.\mathrm{PDL}^{\smile}\right)$. $\mathrm{PDL}^{\smile}\left(\Gamma_{0} ; \Pi_{0}\right)$ is defined over a given set $\Gamma_{0}$ of propositional constants and a set $\Pi_{0}$ of basic modalities. $\left(\Gamma_{0}\right.$ or $\Pi_{0}$ are suppressed whenever clear from the context.) Its syntax is as follows.

* $p_{i}$ is a formula, $i \in \omega$.

$* \perp$ is a formula.

$*$ If $\gamma \in \Gamma_{0}$, then $\gamma$ is a formula.

$*$ If $\chi$ and $\varphi$ are formulae, so is $\neg \chi$ and $\varphi \wedge \chi$.

$*$ If $\chi$ is a formula, $\chi$ ? is a program.

* If $\alpha \in \Pi_{0}$ then $\alpha$ is a program.

$*$ If $\alpha, \beta$ are programs then $\alpha^{*}, \alpha^{\smile}, \alpha ; \beta$ and $\alpha \cup \beta$ are programs as well.

* If $\chi$ is a formula and $\alpha$ a program then $[\alpha] \chi$ and $\langle\alpha\rangle \chi$ are formulae.

(The symbols $\vee, \rightarrow$ and $\leftrightarrow$ are defined as usual.) There are some sublanguages that we shall discuss. The first is the language of Elementary PDL (with Converse), denoted by EPDL (EPDL ${ }^{-}$). It is the $*$-free fragment of PDL (PDL ${ }^{\smile}$ ). We note here that it is expressively equivalent to modal logic (with $\langle\prec\rangle$ and — in the case of converse — also $\langle\succ\rangle$ as basic modalities). Further, the positive fragment of these languages is the fragment where the boolean connectives are only $\wedge$ and $\vee$; whence in particular no occurrences of $\perp, \neg$ or $\rightarrow$.

Let $\Gamma$ be the set of formulae not containing occurrences of variables. These are called the constant formulae. Then $\Gamma_{0} \subseteq \Gamma$. A Kripke-frame is a triple $\mathfrak{F}=\langle F, R, K\rangle$ where $F$ is a set (possibly empty), $R: \Pi_{0} \rightarrow$ $\wp(F \times F)$ a function assigning a binary relation to each modality, and $K$ : $\Gamma_{0} \rightarrow \wp(F)$ a function assigning a subset of $F$ to each constant. Given a Kripke-frame $\mathfrak{F}$, a valuation into $\mathfrak{F}$ is a function $\beta: \operatorname{Var} \rightarrow \wp(F)$, 
assigning a set to each variable. For $x \in F$ we now define:

$$
\begin{array}{llll}
\langle\mathfrak{F}, \beta, x\rangle \vDash p & & \Leftrightarrow & x \in \beta(p) \\
\langle\mathfrak{F}, \beta, x\rangle \vDash \perp & : \Leftrightarrow & \text { false } \\
\langle\mathfrak{F}, \beta, x\rangle \vDash \gamma & : \Leftrightarrow & \gamma \in K(c) \\
\langle\mathfrak{F}, \beta, x\rangle \vDash \neg \chi & : \Leftrightarrow & \langle\mathfrak{F}, \beta, x\rangle \not \models \chi \\
\langle\mathfrak{F}, \beta, x\rangle \vDash \chi \wedge \varphi & : \Leftrightarrow & \langle\mathfrak{F}, \beta, x\rangle \vDash \chi ; \varphi \\
\langle\mathfrak{F}, \beta, x\rangle \vDash[\alpha] \chi & : \Leftrightarrow & \text { if } x R(\alpha) y \text { then }\langle\mathfrak{F}, \beta, y\rangle \vDash \chi \\
\langle\mathfrak{F}, \beta, x\rangle \vDash\langle\alpha\rangle \chi & : \Leftrightarrow & \text { there is } x R(\alpha) y \text { such that }\langle\mathfrak{F}, \beta, y\rangle \vDash \chi
\end{array}
$$

This is complete once we have specified $R(\alpha)$ for programs. We define:

$$
\begin{array}{ll}
R(\alpha \cup \beta) & :=R(\alpha) \cup R(\beta) \\
R(\alpha ; \beta) & :=R(\alpha) \circ R(\beta) \\
R\left(\alpha^{*}\right) & :=\bigcup_{n \in \omega} R(\alpha)^{n} \\
R\left(\alpha^{\smile}\right) & :=R(\alpha)^{\smile} \\
R(\chi ?) & :=\{\langle x, x\rangle:\langle\mathfrak{F}, \beta, x\rangle \vDash \chi\}
\end{array}
$$

(Here, $R^{\smile}:=\{\langle y, x\rangle:\langle x, y\rangle \in R\}$, and $R \circ S=\{\langle x, z\rangle$ : exists $y$ : $\langle x, y\rangle \in R,\langle y, z\rangle \in S\}$.) We write $\mathfrak{F} \vDash \chi$ if for all valuations $\beta$ and all points $x:\langle\mathfrak{F}, \beta, x\rangle \vDash \chi$.

The structures that we are interested in are labelled strings. The $A-$ strings as defined above are not the canonical model structures. Therefore we shall offer a slightly modified definition.

Definition 1. A finite string is a pair $\langle S,<\rangle$, where $S$ is a finite set and $<\subseteq S$ a discrete linear order. A labelled string is a triple $\langle S,<, \ell\rangle$ such that $\langle S,<\rangle$ is a finite string and $\ell: S \rightarrow A$ a function, the so-called labelling function.

The language that we shall use is based on $\Gamma_{0}:=\{\underline{a}: a \in A\}$ and $\Pi_{0}:=\{\prec\}$. We use the shorthand $\succ$ for $\prec^{\smile},<:=\prec^{+}$and $>:=\succ^{+}$. Hence, $\langle\boldsymbol{x}, \beta, w\rangle \vDash\langle\prec\rangle \chi$ if for a successor $v$ of $w:\langle\boldsymbol{x}, \beta, v\rangle \vDash \chi$. Notice that successors are unique if they exist, the same for predecessors.

The $A$-string $\boldsymbol{x}$ with length $n$ is identified with the string $\langle n,<\uparrow$ $n \times n, \boldsymbol{x}\rangle$. It is easy to see that for every finite string there exists one and only one corresponding $A$-string $\boldsymbol{x}$. Moreover, two finite strings are isomorphic if and only if they correspond to the same $A$-string.

The question is now: can we logically describe these structures? The answer is no. The reason is simple: modal languages cannot define connectedness. However, apart from this the situation is as good as it can be. 
Definition 2. Let $\mathfrak{F}=\langle F, R, K\rangle$ be a Kripke-frame. $\mathfrak{F}$ is called connected if the smallest equivalence relation containing all the $R(\alpha), \alpha \in$ $\Pi_{0}$, is the total relation $F \times F$.

Write $\mathcal{V} \vDash \chi$ for a class $\mathcal{V}$ of Kripke-frames if $\mathfrak{F} \vDash \chi$ for all $\mathfrak{F} \in \mathcal{V}$, and $\mathfrak{F} \vDash \Theta$ for a set $\Theta$ of formulae iff $\mathfrak{F} \vDash \chi$ for every $\chi \in \Theta$.

Definition 3. Let $\mathcal{V}$ be a class of Kripke-structures. We say that $\mathcal{V}$ is (finitely) $\mathrm{PDL}^{\smile}$-axiomatizable if there is a (finite) set $\Theta$ of $\mathrm{PDL}^{\smile-}$ formulae such that $\mathfrak{F} \vDash \Theta$ iff $\mathfrak{F} \in \mathcal{V}$. $\mathcal{V}$ is (finitely) pseudo-PDL ${ }^{\smile}$ axiomatizable if there is a (finite) set $\Theta$ of $\mathrm{PDL}^{\smile}$-formulae such that for every connected $\mathfrak{F}: \mathfrak{F} \vDash \Theta$ iff $\mathfrak{F} \in \mathcal{V}$.

Proposition 1. The class of labelled strings with labels in $A$ is pseudo$\mathrm{PDL}{ }^{-}$axiomatizable.

This result is noteworthy because it eliminates the talk of general frames (which we therefore have not defined at all). All connected structures are finite, and by general theorems of modal logic a finite general frame is equivalent to a finite Kripke-frame.

Definition 4. Given a class $\mathcal{V}$ of Kripke-structures, we put Th $\mathcal{V}:=\{\chi$ : $\mathcal{V} \vDash \chi$ \}. This is called the logic of $\mathcal{V}$. Given a set $\Theta$ of $\mathrm{PDL}^{\smile}$-formulae, we write $\operatorname{Mod} \Theta$ for the class of all $\mathfrak{F}$ such that $\mathfrak{F} \vDash \Theta$, and call it the model class of $\Theta$.

In the present context we may think of the models as being labelled strings over some given $A$, and the sets of formulae as theories over such structures. We shall first be interested in the space of all theories before we narrow down on some particular and more realistic ones.

First, let us note that if $\langle S,<, \ell\rangle$ and $\left\langle S^{\prime},<^{\prime}, \ell^{\prime}\right\rangle$ are isomorphic, then they have exactly the same theory. Further, as is well known, if $S \cap S^{\prime}=$ $\varnothing$ and $\chi$ is valid both in $\langle S,<, \ell\rangle$ and in $\left\langle S^{\prime},<^{\prime}, \ell^{\prime}\right\rangle$ then $\chi$ is also valid in $\left\langle S \cup S^{\prime},<\cup<^{\prime}, \ell \cup \ell^{\prime}\right\rangle$. So, all we can expect is that we can discriminate between different $A$-strings. Moreover, two sentences that are not equivalent in the logic of $A$-strings can actually be separated by an A-string:

Lemma 1. Suppose that $\boldsymbol{x}$ is an $A$-string. Then there is a constant EPDL ${ }^{-}$ formula $\chi(\boldsymbol{x})$ such that $\boldsymbol{y} \vDash \chi(\boldsymbol{x})$ iff $\boldsymbol{y}=\boldsymbol{x}$.

Theorem 1. Denote by $\Sigma_{0}$ the logic of $A$-strings. 


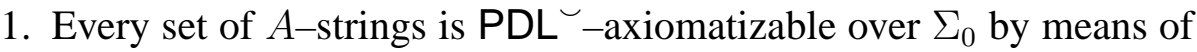
a set of constant formulae.

2. A set of $A$-strings is finitely $\mathrm{PDL}^{\smile}$-axiomatizable over $\Sigma_{0}$ iff it is regular.

We shall not prove this theorem. Suffice it to indicate how a regular language is axiomatized. For a regular term $T$ we define a program $T^{\S}$ inductively as follows.

$$
\begin{array}{ll}
\varnothing^{\S} & :=\perp ? \\
\varepsilon^{\S} & :=\neg \perp ? \\
a^{\S} & :=\prec ; \underline{a} ? \\
(T \cup U)^{\S} & :=T^{\S} \cup U^{\S} \\
(T \cdot U)^{\S} & :=T^{\S} ; U^{\S} \\
\left(T^{*}\right)^{\S} & :=\left(T^{\S}\right)^{*}
\end{array}
$$

Lemma 2. $\boldsymbol{x} \in E(T)$ if and only if $\boldsymbol{x} \vDash[\succ] \perp \rightarrow\left\langle T^{\S}\right\rangle[\prec] \perp$.

The formula defining the regular string language is constant, as is easily checked. So, what we are looking at in sequel are extensions $L$ of $\Sigma_{0}$ by means of finitely many constant formulae.

\section{Phonemic Features}

While phonetics is the study of sounds, phonology is the study of the sound systems of the languages. The sounds of a language are grouped into so-called phonemes. However, the grouping into phonemes is far from easy. A good exposition of the method can be found in Harris [?]. In this section we shall study one particular problem of phonemicization and see how it relates to the logical structure of the phonological system. Let us assume for simplicity that words or texts are realized as sequences of discrete entities called sounds. (So, we do not ask whether e. g. it is appropriate to analyse an affricate as a sequence of a stop and a fricative or as a single sound.) The set of sounds is denoted by $\Sigma$. We said realize since we assume that a word is not simply a sequence of sounds, but a set of such sequences.

Definition 5. $L$ is a language* over $\Sigma$ if $L$ is a subset of $\wp\left(\Sigma^{*}\right)$ such that $\varnothing \notin \Sigma$ and if $W, W^{\prime} \in L$ and $W \cap W^{\prime} \neq \varnothing$ then $W=W^{\prime}$. We call the members of $L$ words. $\boldsymbol{x} \in W$ is called a realization of $W$. For two 
sequences $\boldsymbol{x}$ and $\boldsymbol{y}$ we write $\boldsymbol{x} \sim_{L} \boldsymbol{y}$ if they belong to (or realize) the same word.

One of the aims of phonology is to simplify the alphabet in such a way that words are realized by as few as possible sequences. We proceed by choosing a new alphabet, $P$ and a mapping $\pi: \Sigma \rightarrow P$. The map $\pi$ induces a partition on $\Sigma$. If $\pi(s)=\pi\left(s^{\prime}\right)$ we say that $s$ and $s^{\prime}$ are allophones. $\pi$ induces a mapping of $L$ onto a subset of $\wp\left(P^{*}\right)$ in the following way. For a word $W$ we write $\bar{\pi}[W]:=\{\bar{\pi}(\boldsymbol{x}): \boldsymbol{x} \in W\}$. Finally, $\pi^{*}(L):=\{\bar{\pi}[W]: W \in L\}$. The map $\pi$ must have the following property: if $\boldsymbol{x}$ and $\boldsymbol{y}$ belong to different words, then $\bar{\pi}(\boldsymbol{x}) \neq \bar{\pi}(\boldsymbol{y})$. This gives rise to the following definition.

Definition 6. Suppose $L \subseteq \wp\left(\Sigma^{*}\right)$ is a language* $\pi$ is called discriminating for $L$ if whenever $W, W^{\prime} \in L$ are distinct then $\bar{\pi}[W] \cap \bar{\pi}\left[W^{\prime}\right]=\varnothing$.

Lemma 3. Let $L \subseteq \wp(\Sigma)$ be a language and $\pi: \Sigma \rightarrow P$. If $\pi$ is discriminating for $L, \pi^{*}(L)$ is a language over $P$.

Definition 7. A phonemicization of $L$ is a discriminating map $v: A \rightarrow$ $B$ such that for every discriminating $w: A \rightarrow C$ we have $|C| \geq|B|$. We call the members of $B$ phonemes.

As it turns out, the phonemes are typically not mere sets of sounds. As such, they would otherwise be infinite. However, no speaker of a language has access to infinitely many sounds at any given moment. Rather, phonemes typically are defined by means of articulatory features, which tell us (in an effective way) what sound is associated with what phoneme. For example, English [p] is a sound that is voiceless (this means that the chords do not vibrate while the sound is being pronounced), it is an obstruent (it obstructs the air flow), it is a bilabial (it is pronounced by putting the lips together) and so on. The analysis of this sort ends in the establishment of an alphabet $P$ of abstract sounds classes, defined by means of some articulatory features. These can be modeled in the logical language by means of constants. For example, the feature voiced corresponds to a constant which we call by the same name. Obviously, $\neg$ voiced is the same as being unvoiced. (This need not be the same as being voiceless. We return to the question of intermediate values in Section 6.) This is what we shall take for granted here, even though the establishment of this alphabet is problem laden as well. We shall now return to 
the simpler conception of language as a set of strings; hence, words are now - if you wish - single membered sets. In this case, the language* $L$ is uniquely defined by the language $L^{\diamond}:=\{\boldsymbol{x}:\{\boldsymbol{x}\} \in L\}$.

It might be thought that languages do not possess nontrivial phonemicization maps. This is however not so. For example, English has two different sounds, $[\mathrm{p}]$ and $\left[\mathrm{p}^{h}\right]$. The first occurs after $[\mathrm{s}]$, while the second appears for example word initially before a vowel. It turns out that in English [p] and $\left[\mathrm{p}^{h}\right]$ are not two but one phoneme. To see why, we offer first a combinatorial and then a logical analysis.

Definition 8. Let $L \subseteq A^{*}$ be a language. We define $C_{L}(a):=\{\langle\boldsymbol{x}, \boldsymbol{y}\rangle$ : $\boldsymbol{x} \cdot a \cdot \boldsymbol{y} \in L\}$ and call it the context set of $a$ in $L$.

$a$ and $a^{\prime}$ are said to be in complementary distribution if $C_{L}(a) \cap C_{L}\left(a^{\prime}\right)=$ $\varnothing$. An example is the abovementioned $[\mathrm{p}]$ and $\left[\mathrm{p}^{h}\right]$. Another example is $[c ̧]$ versus $[\chi]$ in German. Both are written ch. However, ch is pronounced $[\chi]$ if occurring after $[\mathrm{a}],[\mathrm{o}]$ and $[\mathrm{u}]$, while it is pronounced $[\mathrm{c}]$ if occurring after other vowels and [r], [n] or [1]. Examples are Licht ['liçt], Nacht [na $\chi \mathrm{t}$ ], echt ['eçt] and acht ['a $\chi \mathrm{t}$ ]. (If you do not know German, here is a short description of the sounds. $[\chi]$ is pronounced like $\mathrm{ch}$ in Scottish English loch. [ç] is pronounced at the same place as y in English yacht, however the tongue is a little higher, that is, closer to the palatum and also the air pressure is somewhat higher, making it sound harder.)

Notice the following. In the language $L_{0}:=\{\mathrm{a} a, \mathrm{~b} b\}$, $\mathrm{a}$ and $\mathrm{b}$ are in complementary distribution. Nevertheless, the map sending both to the same element is not injective. So, complementary distribution is not enough to make two sounds belong to the same phoneme. We shall see below what is. Second, let $L_{1}:=\{\mathrm{ac}, \mathrm{bd}\}$. We may either send a and b to e and obtain the language $M_{0}:=\{$ ec, ed $\}$, or we may send $\mathrm{c}$ and $\mathrm{d}$ to $f$ and obtain the language $M_{1}:=\{\mathrm{af}, \mathrm{bf}\}$. Both maps are phonemicizations, as is easily checked. So, the result is not unique (this has been observed already by Harris [?]). In order to analyse the situation, we have to present a few definitions. The general idea is this. Suppose that $A$ is not minimal for $L$ in the sense that it possesses a noninjective phonemicization. Then there is a pre-phonemicization that conflates exactly two symbols into one. The image $M$ of this map is a regular language again. Now, given the latter we can actually recover for each member of $M$ its preimage under this conflation. What we shall show now is that moreover 
if $L$ is regular there is an explicit procedure telling us what the preimage $i s$. This will be cast in rather abstract terms (compare the discussion of the elimination of features in [263]).

Definition 9. Let $L$ be a dynamic logic. We write $\Delta \Vdash_{L} \delta$ if there is a sequence $\Pi:=\left\langle\pi_{i}: i<n\right\rangle$ such that (a) $\pi_{n-1}=\delta$, (b) for each $i<n-1$, either (i) $\pi_{i} \in L$ or (ii) $\pi_{i} \in \Delta$ or (iii) there exists a $j<i$ and a $\lambda<\kappa$ such that $\pi_{i}=\square_{\lambda} \pi_{j}$, or (iv) there exist $j, k<i$ such that $\pi_{k}=\pi_{j} \rightarrow \pi_{i}$.

The connection between this syntactic definition and the model consequence is as follows.

Theorem 2. Let $L$ be a dynamic logic. Then $\Delta \Vdash_{L} \delta$ iff for all general frames $\mathfrak{F}$ and all valuations $\beta$ : if $\langle\mathfrak{F}, \beta, x\rangle \vDash \Delta$ for every $x \in F$ then $\langle\mathfrak{F}, \beta, x\rangle \vDash \delta$ for every $x \in F$.

Definition 10. Let $L$ be a dynamic logic and $\varphi$ a formula. We say that $\varphi(q)$ globally implicitly defines $q$ in $L$ if $\varphi(q) ; \varphi\left(q^{\prime}\right) \Vdash_{L} q \leftrightarrow q^{\prime}$.

Features that are implicitly defined I have dubbed inessential in [263]. They are in principle not needed in describing the structures; however, we may measure the complexity of their distribution by means of the language in which an explicit definition can be given and in terms of some complexity measures on formulae. If the sets of structures are regular (in terms of the occurring constants), we shall see that the distribution of inessential features can be explicitly defined in $\mathrm{PDL}$. The situation is different in syntax with respect to context free languages (see again [263]).

Definition 11. Let $L$ be a logic and $\varphi(q)$ a formula. Further, let $\delta$ be a formula not containing $q$. We say that $\delta$ globally explicitly defines $q$ in $L$ with respect to $\varphi$ if $\varphi(q) \Vdash_{L} \delta \leftrightarrow q$.

Obviously, if $\delta$ globally explicitly defines $q$ with respect to $\varphi(q)$ then $\varphi(q)$ globally implicitly defines $q$. On the other hand, if $\varphi(q)$ globally implicitly defines $q$ then it is not necessarily the case that there is an explicit definition for it. It very much depends on the logic in addition to the formula whether there is. A logic is said to have the global Bethproperty if for any global implicit definition there is a global explicit definition. Now suppose that we have a formula $\varphi$ and that it implicitly 
defines $q$. Suppose further that $\delta$ is an explicit definition. Then the following is valid.

$$
\Vdash_{L} \varphi(q) \leftrightarrow \varphi(\delta)
$$

The logic $L \oplus \varphi$ defined by adding the formula $\varphi$ as an axiom to $L$ can therefore equally well be axiomatized by $L \oplus \varphi(\delta)$.

Theorem 3. Every logic of a regular string language has the global Bethproperty.

Proof. (We deliver a sketch only.) We have seen that the logic of an arbitrary set of strings is axiomatizable using constant formulae. Now, by an observation of Rautenberg's, it is easily shown that it is enough to establish that the logic of all strings has the global Beth-property (see[267]). Furthermore, this can be reduced to showing that for the test-free PDLtheory of strings. Now, there is a simple trick to eliminate the star: rather than writing $\left\langle\gamma^{*}\right\rangle \chi$ we write an equation $[u](q \leftrightarrow \chi \vee\langle\gamma\rangle q)$, where $q$ is a new variable and $u:=\langle\cup>\cup(\neg \perp)$ ? (the universal modality). These two are equivalent. Using this we can actually reduce $\varphi(p)$ to a conjunction of equations of the form $q \leftrightarrow \chi \vee\langle\prec\rangle \chi^{\prime}$ or of the form $q \leftrightarrow \chi$, where $\chi$ is nonmodal, and both $\chi$ and $\chi^{\prime}$ may or may not contain $q$. Such a system of equations defines a finite automaton in which the variables are sets of states. Such systems can be explicitly solved in PDL using constant formulae (since PDL allows to define regular expressions).

This fails for nonregular string languages, for example $L=\left\{\mathrm{a}^{2^{n}} \mathrm{Ca}^{n}\right.$ : $n \in \omega\}$. The reason why this proof only works for regular languages is that the explicit definition depends on the axiomatization as well. If the axiomatization is infinite, by the described procedure we get an infinite array of formulae. This does not have a regular solution in general. Now, let us return to phonemicization. Let $L$ be given and choose a pair $a$ and $a^{\prime}$ of letters such that the collapse of them into one letter $c$ is a prephonemicization. Call the map $v \cdot \bar{v}[L]$ is a regular language and defined by some expression in the constants $\bar{b}, b \in B$. Now, surely we can write down a definition $\omega(\underline{a})$ of $L$ using these constants and the constant $\underline{a}$ since $\underline{a^{\prime}}$ can be globally defined as $\underline{c} \wedge \neg \underline{a}$. However, we want to have a formula $\chi_{a}$ in the constants $\underline{b}, b \in B$, that defines the distribution of $a$ using only the letters of $B$. We know that the distribution is unique: so we have $\omega(p), \omega(q) \Vdash_{M} p \leftrightarrow q$, since if $\omega(p)$ and $\omega(q)$ is satisfied, we have a string which is in $M$. Since the distribution of the symbols of $B$ 
is given, the distribution of $a$ is unique by assumption. Hence we get a constant formula $\chi$ such that $\omega(p) \Vdash p \leftrightarrow \chi$. This is the desired formula. We summarize.

Corollary 1. Let $L$ be a regular language and $v: A \rightarrow B$ a phonemicization. Then for every $a \in A$ there is a constant formula $\chi_{a}$ using the constants from $B$ such that for every string $\boldsymbol{x} \in L:\langle\boldsymbol{x}, y\rangle \vDash \underline{a}$ iff $\langle\bar{v}(\boldsymbol{x}), y\rangle \vDash \chi_{a}$.

It is clear that $\chi_{a}$ is the context condition of $a$. It follows that $\bar{v}$ induces a regular relation, that is, can be defined by means of a finite state transducer. We shall indicate here that the result is false for languages*. This is so since the distribution of a sound is in general not completely predictable from its context so that its distribution is not even implicitly definable. We shall briefly comment on the notion of a phonemic feature. An articulatory feature is phonemic if it either holds of all sounds of a given phoneme or of none. Phonematic features are clearly essential in the sense of [263].

\section{Positional Features}

In the previous section we have studied the process of introducing a minimal vocabulary to distinguish the sounds of the language. It ended in a definition of a set of phonemes representing classes of sounds. Suppose now that we have defined a set of phonemes; let us include in this list also the syllable boundary marker + and the word boundary marker \#. These are not brackets, they are seperators. Since a word boundary is also a syllable boundary, no extra marking of the syllable is done at the word boundary. Let us now ask what are the rules of syllable and word structure in a language. The minimal assumption is that any combination of phonemes may form a syllable. This turns out to be false. Syllables are in fact constrained by a number of (partly language dependent) principles. This is so since the vocal tract has a certain physiognomy that discourages certain phoneme combinations while it enhances others. These properties also lead to a deformation of sounds in contact, which is called sandhi, a term borrowed from Sanskrit grammar. A particular example of sandhi is assimilation ([np] $>[\mathrm{mp}]$ ). Sandhi rules exist in nearly all languages, but the scope and character varies greatly. Here, we shall call 
sandhi any constraint that is posed on the occurrence of two phonemes (or sounds) next to each other.

Somewhat more general than sandhi are the templates.

Definition 12. Let $A$ be an alphabet. An $n$-template over $A$ (or template of length $n$ ) is a cartesian product of length $n$ of subsets of $A$. A language $L$ is an $n$-template language if there is a finite set $\mathcal{P}$ of length $n$ such that $L$ is the set of words $\boldsymbol{x}$ such that every subword of length $n$ belongs to at least one template from $\mathcal{P}$. $L$ is a template language if there is an $n$ such that $L$ is an $n$-template language.

Obviously, an $n$-template language is an $n+1$-template language. Furthermore, 1-template languages have the form $B^{*}$ where $B \subseteq A$. So the first really interesting class is that of the 2-template languages. It is clear that if the alphabet is finite, we may actually define an $n$-template to be just a member of $A^{n}$. Hence, a template language is defined by naming all those sequences of bounded length that are allowed to occur.

Proposition 2. A language is a template language iff its class of $A-$ strings is axiomatizable by finitely many positive EPDL-formulae.

To make this more realistic, we shall allow also boundary templates. Namely, we shall have a set $\mathcal{P}^{-}$of left edge templates and a set $\mathcal{P}^{+}$of right edge templates. $\mathcal{P}^{-}$lists the admissible $n$-prefixes of a word and $\mathcal{P}^{+}$the admissible $n$-suffixes. Call such languages boundary template languages. Notice that phonological processes are often conditioned by certain boundaries. However, we have added the boundary markers to the alphabet. This effectively eliminates the need for boundary templates in the description here. We have not explored the question what would happen if they were eliminated from the alphabet.

Proposition 3. A language is a boundary template language iff its class of $A$-strings is axiomatizable by finitely many EPDL-formulae.

It follows by a result of Büchi that template languages are regular (which is easy to prove anyhow). However, the language $\mathrm{Ca}^{+} \mathrm{C} \cup \mathrm{da}^{+} \mathrm{d}$ is regular but not a template language.

Of special interest are 2-templates since they simply encode the sandhi conditions. In order not to create confusion, we shall use the somewhat less imaginative term 2-template instead of sandhi. The set of templates effectively names the legal transitions of an automaton that uses the alphabet $A$ itself as the set of states to recognize the language. We shall 
define this notion, using a slightly different concept here, namely that of a partial finite state automaton. This is a quintuple $\mathfrak{A}=\langle I, Q, F, A, \delta\rangle$, such that $A$ is the input alphabet, $Q$ the set (!) of internal states, $I$ the set of initial states, $F$ the set of accepting states and $\delta \subseteq A \times Q \rightarrow Q$ a partial function. $\mathfrak{A}$ accepts $\boldsymbol{x}$ if there is a computation from some $q \in I$ to some $q^{\prime} \in F$ with $\boldsymbol{x}$ as input. $\mathfrak{A}$ is a 2-template if $Q=A$ and $\delta(a, b)$ is either undefined or $\delta(a, b)=b$.

The reason for concentrating on 2-template languages is the philosophy of naturalness explained in [263]. Basically, grammars are natural if the nonterminal symbols can be drawn from the set of of terminal symbols. Alternatively put: for every nonterminal $X$ there is a terminal $a$ such that for every $X$-string $\boldsymbol{x}$ we have $C_{L}(\boldsymbol{x})=C_{L}(a)$. For a regular grammar this means in essence that a string beginning with $a$ has the same distribution as the letter $a$ itself. A moment's reflection reveals that this is the same as the property of being 2-template. Notice that the $2-$ template property of words and syllables was motivated from the nature of the articulatory organs, and we have described a parser that recognizes whether something is a syllable or a word. Although it seems prima facie plausible that there are also auditory constraints on phoneme sequences we know of no plausible constraint that could illustrate it. We shall therefore concentrate on the former. What we shall show now is that syllables are not 2-template. This will motivate either adding structure or adding more features to the description of syllables. These features are necessarily nonphonemic.

We shall show that nonphonemic features exist by looking at syllable structure. It is not possible to outline a general theory of syllable structure. However, the following sketch may be given (see [178]). The sounds are aligned into a so called sonority hierarchy, which is as follows. (vd. = voiced, vl. $=$ voiceless.)

$$
\begin{aligned}
& \text { dark vowels }>\text { mid vowels }>\text { high vowels }>\text { r-sounds } \\
& \text { [a], [o] [æ], [œ] } \quad[\mathrm{i}],[\mathrm{y}] \quad[\mathrm{r}] \\
& >\text { nasals; laterals }>\text { vd. fricatives }>\text { vd. plosives }>\text { vl. fricatives } \\
& {[\mathrm{s}],[\mathrm{f}] \quad[\mathrm{m}],[\mathrm{n}] ;[\mathrm{l}] \quad[\mathrm{z}],[3] \quad[\mathrm{b}],[\mathrm{d}]} \\
& >\text { vl. plosives } \\
& {[\mathrm{p}],[\mathrm{t}]}
\end{aligned}
$$


The syllable is organized as follows.

Syllable Structure. Within a syllable the sonority increases monotonically and then decreases.

This means that a syllable must contain at least one sound which is at least as high as all the others in the syllable. It is called the sonority peak. We shall make the following assumption that will simplify the discussion.

Sonority Peak. The sonority peak can be constituted by vowels only.

This wrongly excludes the syllable [krk], or [dn]. The latter is heard in the German verb verschwinden [fee' $\left.\int w i n d n\right]$. (The ' $e$ ' that appears in writing is hardly ever pronounced.) However, even if the assumption is relaxed, the problem that we shall address will remain.

The question is: how do we implement these constraints? There are two ways of doing so that interest us here. (a) We state them as such. Indeed, it is not hard to come up with a constant $\mathrm{PDL}{ }^{-}$-formula that describes the facts as stated. (For lovers of MSO: the same can obviously be done using MSO.) This is the descriptive approach. (b) We 'code' them in the sense of [261]. This means that we add some features in such a way that the resulting restrictions become specifiable by 2 -templates.

The approach under (b) has some motivation as well. The added features can be identified as states of a productive (or analytic) device. Thus, while the solution under (a) tells us what the constraint actually is, the approach under (b) gives us features by which we can identify as (sets of) states of a (finite state) machine that actually parses or produces the structures. Let us see how this goes.

Suppose first that we have a natural language. Obviously, the constraints are $\mathrm{PDL}{ }^{-}$-axiomatizable. So the really interesting part is to naturalize an arbitrary regular language. This can be done in a very simple way, described basically in [261]. We shall introduce basic constants to eliminate all recursion. Suppose we have a constraint $\chi$, where $\chi$ is a constant formula. 
Definition 13. The Fisher-Ladner closure of $\chi$ is defined as follows.

$$
\begin{array}{ll}
F L\left(p_{i}\right) & :=\left\{p_{i}\right\}, \\
F L(\gamma) & :=\{\gamma\}, \\
F L\left(\chi \wedge \chi^{\prime}\right) & :=\left\{\chi \wedge \chi^{\prime}\right\} \cup F L(\chi) \cup F L\left(\chi^{\prime}\right), \\
F L(\langle\alpha \cup \beta\rangle \chi) & :=\{\langle\alpha \cup \beta\rangle \chi\} \cup F L(\langle\alpha\rangle \chi) \cup F L(\langle\beta\rangle \chi), \\
F L(\langle\alpha ; \beta\rangle \chi) & :=\{\langle\alpha ; \beta\rangle \chi\} \cup F L(\langle\alpha\rangle\langle\beta\rangle \chi), \\
F L\left(\left\langle\alpha^{*}\right\rangle \chi\right) & :=\left\{\left\langle\alpha^{*}\right\rangle \chi\right\} \cup F L\left(\langle\alpha\rangle\left\langle\alpha^{*}\right\rangle \chi\right) \cup F L(\chi), \\
F L(\langle\varphi ?\rangle \chi) & :=\{\langle\varphi ?\rangle \chi\} \cup F L(\varphi) \cup F L(\chi), \\
F L(\langle\alpha\rangle \chi) & :=\{\langle\alpha\rangle \chi\} \cup F L(\chi), \quad \alpha \text { basic. }
\end{array}
$$

The Fisher-Ladner closure covers only PDL-formulae. To take care of the converse we observe the following.

$$
\begin{array}{ll}
R\left((\alpha \cup \beta)^{\smile}\right) & =R\left(\alpha^{\smile} \cup \beta^{\smile}\right), \\
R\left((\alpha ; \beta)^{\smile}\right) & =R\left(\beta^{\smile} ; \alpha^{\smile}\right), \\
R\left(\left(\alpha^{*}\right)^{\smile}\right) & =R\left(\left(\alpha^{\smile}\right)^{*}\right), \\
R\left((\varphi ?)^{\smile}\right) & =R(\varphi ?) .
\end{array}
$$

This allows to factually eliminate the converse at the expense of adding just the converse of the basic programs. This is what we shall do first. The next step is to introduce a constant $c(\sigma)$ into the language for each member $\sigma$ of the Fisher-Ladner closure of our formula $\chi$. To ensure the correct distribution of the constants, the following formulae must be added to the logic (so, we first expand the language and then add some more axioms):

$$
\begin{aligned}
& c(\neg \sigma) \quad \leftrightarrow \quad \neg c(\sigma) \\
& c(\sigma \wedge \tau) \quad \leftrightarrow \quad c(\sigma) \wedge c(\tau) \\
& c(\langle\varphi ?\rangle \sigma) \leftrightarrow c(\varphi) \wedge c(\sigma) \\
& c(\langle\alpha \cup \beta\rangle \sigma) \leftrightarrow c(\langle\alpha\rangle \sigma) \vee c(\langle\beta\rangle \sigma) \\
& c(\langle\alpha ; \beta\rangle \sigma) \leftrightarrow c(\langle\alpha\rangle\langle\beta\rangle \sigma) \\
& c\left(\left\langle\alpha^{*}\right\rangle \sigma\right) \quad \leftrightarrow \quad c\left(\langle\alpha\rangle\left\langle\alpha^{*}\right\rangle \sigma\right) \vee c(\sigma) \\
& c(\langle\prec\rangle \sigma) \quad \leftrightarrow \quad\langle\prec\rangle c(\sigma) \\
& c(\langle\succ\rangle \sigma) \quad \leftrightarrow \quad\langle\succ\rangle c(\sigma)
\end{aligned}
$$

We call these formulae cooccurrence restrictions. After the introduction of these formulae as axioms, the equivalences $\sigma \leftrightarrow c(\sigma)$ are provable for every $\sigma \in F L(\chi)$. In particular, $\chi \leftrightarrow c(\chi)$ is provable. This means that we can eliminate $\chi$ in favour of $c(\chi)$. The formulae that we have just added, do not contain any of the program constructors: ?, $\cup, ;$, or ${ }^{*}$. We only 
have the most simple axioms, stating that some constant is true before or after another. The language is based on the set of constants $\Gamma_{0}$, containing $F L(\chi)$ and $\Pi_{0}=\{\prec, \succ\}$. The axioms of the structures consist in $\Sigma_{0}$ plus $c(\chi)$ and the list of cooccurrence restrictions established above. (The reader is made aware of the fact that we might have to introduce the constants $c([\succ] \perp)$ and $c([\prec] \perp)$ to make this work. These constants effectively mark the beginning and the end of the string. This fact is reflected in the set $\nabla_{\chi}$ in that there is no pair $\left\langle\gamma, \gamma^{\prime}\right\rangle$ where $\gamma \vdash[\succ] \perp$ or $\gamma^{\prime} \vdash[\prec] \perp$.) The logic is called $\Lambda_{\chi}$. For a set $\Theta \subseteq \Gamma_{0}$ put

$$
p(\Theta):=\bigwedge_{\gamma \in \Theta} \gamma \wedge \bigwedge_{\gamma \in \Gamma_{0}-\Theta} \neg \gamma .
$$

Let $\Xi$ consist of all $p(\Theta)$ which are consistent in this logic. Finally, let

$$
\begin{gathered}
\nabla_{\chi}:=\left\{\left\langle p(\Theta), p\left(\Theta^{\prime}\right)\right\rangle: \Lambda_{\chi} \not \models p(\Theta) \rightarrow[\prec] \neg p\left(\Theta^{\prime}\right)\right. \\
\text { and } \left.\Lambda_{\chi} \not \models p\left(\Theta^{\prime}\right) \rightarrow[\succ] \neg p(\Theta)\right\} .
\end{gathered}
$$

We define a map from $\Xi$ to the original alphabet $A$ by

$$
\nu(p(\Theta)):=a, \text { if } \Lambda_{\chi} \vdash p(\Theta) \rightarrow \underline{a} .
$$

For a sequence $\boldsymbol{x} \in \Xi^{*}$ of atoms we write $\bar{\nu}(\boldsymbol{x})$ for the letter by letter translation.

Lemma 4. $\boldsymbol{x} \vDash \chi$ if and only if there is a $\boldsymbol{y} \in \Xi^{*}$ such that $\bar{\nu}(\boldsymbol{y})=\boldsymbol{x}$ which satisfies $\nabla_{\chi}$.

The following is an equivalent of the theorem in [261] about factorization of nonlocal dependencies in syntax into local dependencies.

Theorem 4. Any regular language is the homomorphic image of a boundary 2-template language.

So, we only need to add features. Phonological string languages are regular, so this method can be applied. Let us see how we can find a 2template solution for the sonority hierarchy. We introduce a feature $\alpha$ and its negation $-\alpha$. We start with the alphabet $P$, and let $C \subseteq P$ be the set of consonants. The new alphabet is

$$
\Xi:=P \times\{-\alpha\} \cup C \times\{\alpha\}
$$


Let $\operatorname{son}(a)$ be the sonoricity of $a$.

$$
\begin{aligned}
\nabla:= & \left\{\left\langle\langle a, \alpha\rangle,\left\langle a^{\prime}, \alpha\right\rangle\right\rangle: \operatorname{son}(a) \leq \operatorname{son}\left(a^{\prime}\right)\right\} \\
\cup & \left\{\left\langle\langle a,-\alpha\rangle,\left\langle a^{\prime},-\alpha\right\rangle\right\rangle: \operatorname{son}(a) \geq \operatorname{son}\left(a^{\prime}\right)\right\} \\
& \cup\left\{\left\langle\langle a, \alpha\rangle,\left\langle a^{\prime},-\alpha\right\rangle\right\rangle: a^{\prime} \notin C\right\} \\
\cup & \left\{\left\langle\langle a, \gamma\rangle,\left\langle a^{\prime}, \gamma^{\prime}\right\rangle\right\rangle: a \in\{+, \#\}, \gamma, \gamma^{\prime} \in\{\alpha,-\alpha\}\right\}
\end{aligned}
$$

As it is now, any subword of a word is in the language. We need to mark the begin and end of a sequence in a special way, as described above. This detail shall be ignored here.

$\alpha$ has a clear interpretation: it signals the rise of the sonoricity. It has a natural correlate in what de Saussure calls explosive articulation. A phoneme carrying $\alpha$ is pronounced with explosive articulation, a phoneme carrying $-\alpha$ is pronounced with implosive articulation. (See de Saussure [?].) So, $\alpha$ actually has an articulatory (and an auditory) correlate. But it is a nonphonemic feature; it has been introduced in addition to the phonemic features in order to constrain the choice of the next phoneme. As de Saussure remarks, it makes the explicit marking of the syllable boundary unnecessary. The syllable boundary is exactly where the implosive articulation changes to explosive articulation. However, some linguists (for example van der Hulst [223]) have provided a completely different answer. For them, a syllable is structured in the following way.

$$
\text { [onset [nucleus coda]] }
$$

So, the grammar that generates the phonological strings is actually not a regular grammar but context free (though it makes only very limited use of phrase structure rules). $\alpha$ marks the onset, while $-\alpha$ marks the nucleus together with the coda (which is also called rhyme). So, we have three possible ways to arrive at the constraint for the syllable structure: we postulate an axiom, we introduce a new feature, or we assume more structure. The feature that corresponds to a structural part may be called a positional feature. It is distinct from the kind of feature that we shall look at next.

\section{Vowel Harmony}

The last section has shown that the sequence of phonemes inside a syllable is regulated and that the rules can either be explained by a constraint 
(= axiom) or by some new features, which are however not phonemic. Yet, as linguists have assumed anyway, a syllable is structured, and so the distribution of a phoneme in a syllable can be once again reshaped into a phenomenon of generalized sandhi. This is, by the way, the approach that Government Phonology effectively takes (see for example [244]). The conditions on sequences of phonemes are stated in terms of structure and adjacency between constituents. Also Autosegmental Phonology mainly discusses sandhi. It is therefore of some importance to exhibit phenomena that cannot be reduced to sandhi in any plausible way. One such phenomenon is vowel harmony. Before we enter the theoretical discussion we shall outline what the facts are. (The interested reader is referred to Lass [289] on phonology and and Polgárdi [361] on vowel harmony in general.)

\begin{tabular}{|l||l|}
\hline & i e u y a æ o $\emptyset$ \\
\hline \hline high & +-++--++ \\
mid & -+----++ \\
back & --+-+-+- \\
round & -+++-++ \\
Table 1. The Vowels of Finnish
\end{tabular}

The clearest system of vowel harmony is found in Finnish and Turkish. We shall outline the Finnish system. The Finnish vowel system is shown in Table 1. Each of these vowel exists also as a long vowel. The table also shows an analysis into distinctive features. The first two specify the height of the tongue body (plus - concomitantly - the degree of mouth aperture), the third specifies the horizontal position of the tongue body, and the fourth specifies the so-called lip attitude. From an articulatory point of view the lip attitude is — within bounds — independent from the tongue position.

These vowels falls into three distinct classes, which we shall call neutral, back harmonic and front harmonic. [e] and [i] are neutral, [a], [o] and [u] are back harmonic, while [æ], [ø] and [y] are front harmonic. As a rule, words in Finnish do not contain both a positive and a negative harmonic vowel. For example, osake (share), asema (station), kysymys (question), and lääkäri (doctor) are (actual) Finnish words, but asemö is not even a possible Finnish word, since it contains 
the back harmonic vowel [a] and the front harmonic [ø]. The value of the harmony feature corresponds with the position of the tongue. In front harmonic vowels the tongue root is positioned in direction to the teeth, in neutral vowels it is in mid position, and in back harmonic vowels it is further back. The neutral vowels are in addition unrounded; however, this applies as well to [a] and [æ]. We note in passing that harmony does not apply in compounding. So the harmony requirement is strictly word bound. For example, osakeyhtiö (shareholder company) is a Finnish word, consisting of the two words osake (share) and yhtiö (union), both of which are harmonious. Technically, harmony has a so-called $d o-$ main. The domain of harmony is the subsequence within which it applies. In Finnish this is the word. However, notice that from a technical perspective, compound words are counted as two separate words. One way to achieve this distinction is to add a separate boundary marker to mark the word boundaries inside compounds. The details are not so important here, however.

Finnish has various affixes (typically suffixes). An affix can be neutral, for example the translativ suffix ksi. Or it can be non-neutral, like the inessive suffix. In that case it has two forms, a back harmonic form and a front harmonic form. For example, the inessive case suffix has the two forms ssa and ssä. The front harmonic form is the default; it is added also to those stems which are harmonically neutral. For example, hissi is neutral, so we have hississä and not hississa. The positive harmonic form is used if the word to which the ending is affixed contains a back harmonic vowel.

The Hungarian system is less regular than the Finnish one. First, suffixes are either immutable (the causative ért), or they possess two forms (the inessive ban, ben), or three (the superessive on, en, ön). This im-

\begin{tabular}{|l||l|l|l|}
\hline & causative & inessive & superessive \\
\hline \hline a ház (the house) & a házért & a házban & a házon \\
a föld (the soil) & a földért & a földben & a földön \\
a kürt (the horn) & a kürtért & a kürtben & a kürten \\
\hline
\end{tabular}

Table 2. Three Grades of Harmony in Hungarian

plies that we have a three grade harmony. We have back harmonic vowels $([\mathrm{a}],[\mathrm{o}],[\mathrm{u}])$, neutral vowels $([\varepsilon],[\mathrm{e}],[\mathrm{i}])$ and front harmonic vowels 
([æ], [ø]). However, some suffixes are sensitive to the contrast back/nonback, others to the contrast back/neutral/front. The second complication is that there are roots consisting of neutral vowels that trigger back harmony, and other that trigger front (or non-back) harmony. The word ví z (water) triggers front harmony (a vízben), likewise the word a kés (the knife). On the other hand, kín (torture) and cél (aim) trigger back harmony.

In general, languages showing vowel harmony have two sets of vowels, say $A$ and $B$, and only vowels belonging to the same set may occur in the same harmonic domain. The domains for Finnish are the words, but there are other choices in other languages. The domains change throughout languages, and so do the sets $A$ and $B$. They may be disjoint (in Turkish) but need not be, as in Finnish and Hungarian. A vowel is neutral if it belongs to both sets. Neutral vowels can be transparent or opaque. A neutral vowel is opaque if vowels to its left need not harmonize with vowels to its right. So, it is opaque if harmonic domains do not cross it. According to a general observation by van der Hulst and Smith [224], if neutral vowels possess the harmony feature, then they are transparent for harmony (that is, harmony disregards them completely). Their generalization uses the so-called dependency phonology framework. In dependency phonology, vowels are created by combining certain basic vowels, here A, I, and U. Polgárdi [361] claims that Finnish has I-harmony. Namely, neutral and front harmonic vowels possess the $\mathbf{I}$-feature, back harmonic vowels lack it. It is predicted that therefore the Finnish neutral vowels are transparent. However, as Polgárdi acknowledges, inasmuch as this observation is correct, no theory so far has a good explanation for it. For as we shall see below, any specification of a harmony feature on the neutral vowels leads to opacity!

Finally, all languages also have loanwords. These may at times violate harmony. For example, Turkish otobüs (bus) is not harmonic (it should otherwise be otobus). Similarly, dekor (stage design) and buket (bouquet) (see [251]). The rescue rule for vowel harmony is then that the last non-neutral vowel determines the vowel harmony. So, ot obüs has front harmony, since $\ddot{u}$ is front. This rule operates in all of the three languages under discussion here. 


\section{Memory Features}

A moment's reflection shows that there is no set of 2-templates that accounts for vowel harmony in Finnish or Hungarian. Basically, the harmony of a vowel however is in general not retrievable from the preceding phoneme because that phoneme may be a consonant or a neutral vowel. For example, the occurrence of [a] and [ä] in the inessive suffix s sa/s sä is after [s]. So, nothing will tell us whether to put [a] or [ä]. Suppose now that we have a syllable containing the vowel [ä]. How can the information that we have a front harmonic vowel be passed to the next vowels if there are intervening consonants? There is, as is easily seen, only one solution: we must assume that there are several kinds of consonants. For example, the consonant $[\mathrm{t}]$ splits into three different consonants, which we may write as $\left[\mathrm{t}^{+}\right],\left[\mathrm{t}^{0}\right]$ and $\left[\mathrm{t}^{-}\right]$. This we do for all non-neutral phonemes, excluding the word boundary. The consonants now carry the information as to whether the previous vowel was back, front or neutrally harmonic. This feature is passed on to the next consonant to the right, and so on. Notice, that we also have to assume that there are three kinds of neutral vowels, as we need to pass on the harmony features across vowels. The harmony feature is changed when we hit \#. It is clear that the feature just introduced is not a phonemic feature. It distinguishes sounds within a phoneme.

However, phonologists have observed that there are phonological processes that seem to skip intervening phonemes without being nonlocal. In this section we will review a very influential theory of this kind, namely Autosegmental Phonology (AP). The exact details may differ from author to author, but the discussion here is largely independent of the differences. For a formal exposition see Kornai [?]. From a phonological point of view the features that we have just introduced do not exist. They play no discriminatory role whatsoever. So, they are nonphonemic. One may therefore try a different tack. In autosegmental phonology, we think of the phonemes as being laid out in a skeleton. The skeleton contains a slot for each phoneme but does not list any properties of it. (The skeleton is for our purposes just a linear order, for example $\langle n,<\rangle$. The members of the set are called slots.) The properties of the occurring sounds are specified in certain tiers. There are various tiers, some that specify the manner of articulation, another the place of articulation, and so on. In the ideal case a tier is responsible for the distribution of only one feature. 
Each tier is a labelled linear order. Additionally, between the skeleton and the tiers there exist correspondence relations that are non-crossing in the following sense.

Definition 14. Let $\mathfrak{S}=\langle S,<\rangle$ and $\mathfrak{S}^{\prime}=\left\langle S^{\prime},<^{\prime}\right\rangle$ be two linear orders and $R \subseteq S \times S^{\prime}$ a relation. We say that $R$ is non-crossing if there are no two pairs $x, y \in S$ and $x^{\prime}, y^{\prime} \in S^{\prime}$ such that (a) $x<y$ and $y^{\prime}<^{\prime} x^{\prime}$ and (b) $x R x^{\prime}$ and $y R y^{\prime}$.

Autosegmental theory is a theory about the number of tiers and their various associations. It is assumed that the tiers are hierarchically ordered and that there is a relation only between two tiers that are in immediate domination. For example, the skeleton immediately dominates the root tier, and so a correspondence between the slots of the skeleton and the root tier must be given. The root tier immediately dominates the laryngeal tier, so again correspondences between slots in the respective tiers must be given. The correspondence between the slots in the metrical tier and the slots in the laryngeal tiers is the composition of the relations just given. We can have a single slot in one tier correspond to two or more slots in another. For example, an affricate may be analyzed in the root tier as consisting of two slots, while metrically it consists only of a single one. On the other hand, a long vowel may have two slots in the metrical tier while only one in the root tier. Some slots may also have no correspondent slots in another tier.

The tiers are thought of as descriptions of the time-dependent behaviour of some (segmentable) parts of the vocal tract. To use a metaphor: The skeleton is the conductor, the tiers are the instruments of the orchestra that play according to the score and the beat given by the conductor. The crucial assumption is the following. A phoneme either associates with a tier or it does not. If it does not, then we find that the slot in the metrical tier has no correlate in the given tier. This would solve the problem of Finnish right away. For example, we may assume a harmony tier for Finnish, where all and only the harmonic vowels have slots (hence, there are no slots for neutral vowels there, nor any for consonants). Then on this tier, the vowels turn out to be adjacent, and the need for distinguishing harmonizing consonants disappears. Moreover, one may assume that the harmonizing vowels associate with the same slot in the harmony tier (so we would have one blob per word on the harmony tier, see Figure 1 (a)). (For an analysis of Hungarian see Kornai [?] build- 
ing on [?]. The solution offered in [?] to solve the blocking of harmony spreading under compounding is different from the one proposed here. Also, Kornai (p. c.) takes a more abstract stance concerning the nature of tiers than we do here.)

The rationale behind AP is the following. Some parts of the articulatory organs may remain inert while a certain sound is being produced. For example, we may pronounce [k] with varying lip rounding, without any phonemic difference. Hence, we say that $[\mathrm{k}]$ does not associate with the tier that regulates lip attitude. So, lip attitude can spread across [k]. Similarly, the vocal chord can be seen as an independent unit, just like the tongue root or the lips. We can produce consonants with or without voicing, and we can produce vowels with or without lip rounding and with different tongue root positions. Not everything goes, as we shall see in a minute. However, let this be so. Then we may assume that the tiers actually are the representations of the different motor components. Now consider the (artificial) words [oto] and [ete]. We can observe that in the first word the lips remain rounded during the pronunciation of the [t] and in the second they remain unrounded. Now try the words [ote] and [eto]. Here, the consonant [ $t$ ] is pronounced using a lip position intermediate between that of $[\mathrm{e}]$ and that of [o]. In other words, the lip rounding changes continuously from one position to another, independently of the consonant in between. Let us assume that there is a lip rounding tier. Then it contains a slot for [e] and [o] but none for [t]. Thus the lip positions are fixed only at the points of utterance for [e] and [o], and simply change continuously in between. The the motor component responsible for the lip rounding has to know only at what moments it must assume which lip position, the rest is automatic and independent (see Figure 1 (b)).

In this way we can now understand how harmony is turned into a contact phenomenon. All we need to assume is that there is a motor component corresponding to the harmony tier, which controls the value of the harmony feature. Since the consonants have no slot in the harmony tier, the vowels are immediately adjacent, and we need not posit various kinds of consonants. Now we shall try to answer the following questions:

1. Is there a more conventional way to analyse AP?

2. Is the analysis of Finnish just given plausible within AP? 
Fig. 1. An Autosegmental Analysis

(a)

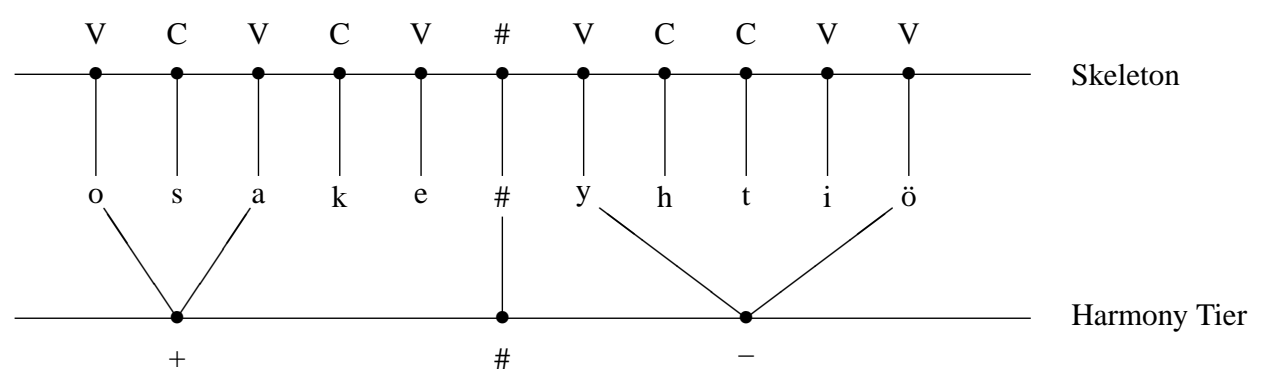

(b)

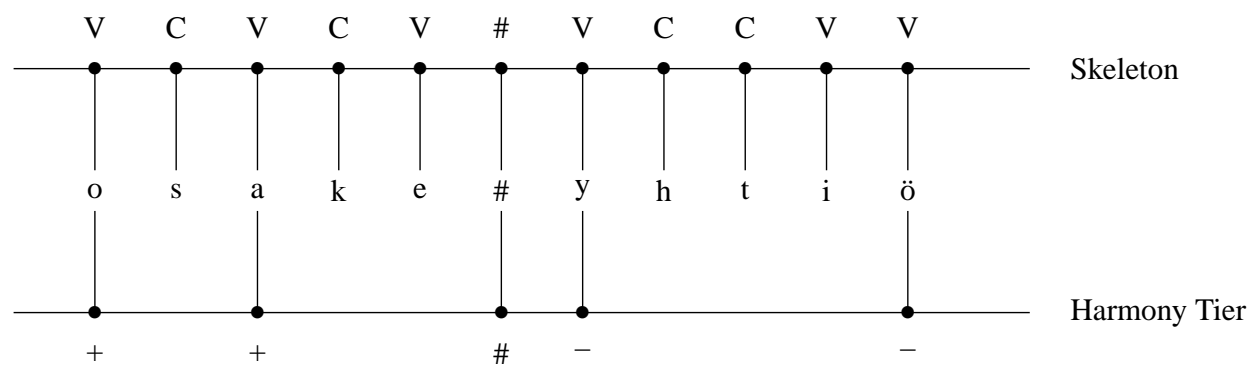

(c)

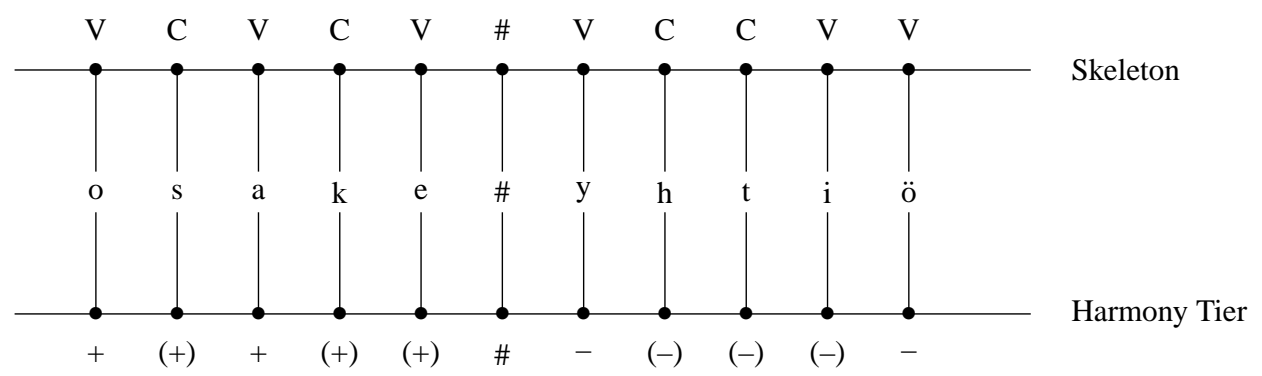


To answer the first, we observe that the nonassociation to a tier is the central instrument of AP. We can reproduce the effect by allowing some more values in the tier: $(+)$ and $(-) .(+)$ means that the last phoneme in the skeleton that associated with that tier had value + . Similarly for $(-)$. (See Figure 1 (c). Some interpretation must be found for phonemes at the left edge.) Given these features, we can simply eliminate the assocation lines and make all tiers structurally isomorphic. The effect that we intended, namely to spread the effect of a phoneme across nonassociating phonemes is established in this way too. So, this interpretation boils down to a conventional analysis in terms of phonemic features and some other features, which we shall call memory features. Let $\alpha$ be a property, say back. We introduce two constants, $c(\alpha)$ and $d(\alpha)$, with this property. Further we introduce the following abbreviations:

$$
\begin{aligned}
& \alpha^{+}:=c(\alpha) \wedge \neg d(\alpha) \\
& \alpha^{-}:=\neg c(\alpha) \wedge d(\alpha) \\
& \alpha^{0}:=c(\alpha) \wedge d(\alpha) \\
& \alpha^{\sharp}:=\neg c(\alpha) \wedge \neg d(\alpha)
\end{aligned}
$$

$\alpha^{+}$denotes the sounds associating positively with property $\alpha, \alpha^{-}$the sounds associating negatively with $\alpha . \alpha^{0}$ denotes the sounds that do not associate with property $\alpha$, and $\alpha^{\sharp}$ those that associate neither positively nor negatively with $\alpha$. Now put

$$
\begin{array}{ll}
\operatorname{hold}\left(\alpha^{+}\right) & :=\left\langle\succ ;\left(\alpha^{0} ? ; \succ\right)^{*}\right\rangle \alpha^{+} \\
\operatorname{hold}\left(\alpha^{-}\right) & :=\left\langle\succ ;\left(\alpha^{0} ? ; \succ\right)^{*}\right\rangle \alpha^{-} \\
\operatorname{hold}\left(\alpha^{\sharp}\right) & :=\left\langle\succ ;\left(\alpha^{0} ? ; \succ\right)^{*}\right\rangle \alpha^{\sharp}
\end{array}
$$

We call these features memory features. The formula hold $\left(\alpha^{+}\right)$is true at $x$ iff the closest predecessor of $x$ associating with $\alpha$ associates positively with $\alpha$.

Finnish Vowel Harmony.

(Domain.) $c(\sharp) \rightarrow \alpha^{\sharp}, c(+) \rightarrow \alpha^{0}$.

(Value.) hold $\left(\alpha^{+}\right) \rightarrow \neg \alpha^{-}$, hold $\left(\alpha^{-}\right) \rightarrow \neg \alpha^{+}$.

These postulates specify first the domain of the harmony and then what harmonizes with what.

From the standpoint of a 'parser' the feature hold $\left(\alpha^{+}\right)$(hold $\left(\alpha^{-}\right)$, $\left.\operatorname{hold}\left(\alpha^{\sharp}\right)\right)$ characterize states where the last associating sound was an $\alpha^{+}$ 
$\left(\alpha^{-}, \alpha^{\sharp}\right)$ sound. Notice that the features $(+)$ and (-) correspond roughly to the hold-features. Therefore, the 'coding' of the harmony yields these features.

\section{Morphophonemic Features}

There remains the question whether we have chosen a proper analysis of Finnish in AP. Notice that the memory features are claimed to have a phonetic reality. Hence, from a phonetic point of view it does make sense to annotate sounds with these features. The plausibility of the analysis of Finnish with a harmony autosegment rests on the question of whether some distinctive feature of the harmonious vowels are retained across all other phonemes. This is so if and only if no other (intervening) sound has that feature. Unfortunately, evidence speaks against that. First, the harmony feature is determined by the tongue position, and since neutral vowels are pronounced in mid position, they should actually override the features of the harmonious vowels. Secondly, also some consonants are pronounced with different tongue positions (compare $[\mathrm{k}]$ and $[\mathrm{t}]$ ). To make life worse, we need an explanation for the fact that if there is no back vowel present, harmony is front. Actually, the logical reformulation shares the same problem with AP. Using the present mechanisms, there is no way to express the fact that if a word has only neutral vowels, the suffix has front harmony. The crucial bit that is missing is the fact that the word has no choice for the harmony, while the suffix does. It is therefore unavoidable that the representation contains an indication of the fact that the item in question can possibly harmonize.

At this point it is useful to bring Hungarian into the discussion. We have seen that Hungarian suffixes can show different kinds of harmony. Furthermore, there exist roots with neutral vowels that trigger front harmony, others trigger back harmony. All this must be marked in the lexicon, since there is no (principled) way to predict the possible harmony from the string alone. This necessitates the introduction of morphophonemic features. They are features attributed to the lexical items that control their harmonic behaviour. 


\section{Conclusion}

We have compared various approaches to phonological structure: constraints (= axioms), templates (= cooccurrence constraints) and autosegmental phonology. These approaches are of different character, and they generate different sets of languages. The template languages are weaker than the autosegmental languages, which in turn are weaker than the axiomatically definable ones, which are all the regular languages. These inclusions hold on condition that all used features must be phonemic. What this tells us is that some principles of well formedness go beyond mere local 'sandhi' and express global facts of the phonological string, like harmony. 


\section{References}

1. E. Aarts and K. Trautwein, Non-associative Lambek Categorial Grammar in polynomial time, in: [56].

2. Samson Abramsky and Achim Jung. Domain theory, in [486].

3. V.M. Abrusci and C.Casadio, Proceedings of the 1996 Roma Workshop, 1996.

4. Johan van Benthem, Exploring Logical Dynamics, CSLI, 1996.

5. Carlos Areces, Logic, Engineering, PhD thesis, ILLC Amsterdam, 2000

6. Ron Aharoni, König's duality theorem for infinite bipartite graphs, Journal of the London Mathematical Society, (Second Series), 29, 1984, p. 1-12.

7. Ron Aharoni, Menachem Magidor, and Richard A. Shore, On the strength of König's duality theorem for infinite bipartite graphs, Journal of Combinatorial Theory, Series B, 54, 1992, p. 257-290.

8. A. Aho and J. Ullman, The theory of parsing, translation, and compiling, Prentice Hall, 1972.

9. K. Ajdukewicz, Die syntaktische Konnexität, Studia Philosophica, 1, 1935, p. 1-27.

10. C. Alchourrón, Philosophical foundations of deontic logic and the logic of defeasible conditionals, in: [326, p. 43-84].

11. C. Alchourrón and E. Bulygin, The expressive conception of norms, in: [209, p. 95-124].

12. C. Alchourrón, P. Gärdenfors and D. Makinson, On the logic of theory change: partial meet contraction and revision functions, The Journal of Symbolic Logic, 50, 1985, p. 510530.

13. C.A. Anderson, The paradox of the knower, Journal of Philosophy, 6, 1983, p. 338-356.

14. R. J. Aumann, Game Theory, in: [121, p. 1-53].

15. R. J. Aumann, and S. Hart, (eds.) Handbook of Game Theory with Economic Applications, vol. 1-3., Elsevier, Amsterdam, p. 1992-1998.

16. J. Autebert, J. Berstel and L. Boasson, Context-Free Languages and Pushdown Automata, in: [401]

17. Mark Baker, Unmatched Chains and the Representation of Plural pronouns, Journal of Semantics, 1, 1992, p. 33-74.

18. Chris Baker and Geoffrey Pullum, A theory of Command Relations, Linguistics and Philosophy, 13, 1990, p. 1-34.

19. W. Balzer, C.U. Moulines (eds.), Structuralist Theory of Science. Focal Issues, New Results, Berlin, New York, 1996.

20. W. Balzer, C.U. Moulines, J. Sneed, An Architectonic for Science, Dordrecht, 1987.

21. W. Balzer, G. Zoubek, On Electrons and Reference, Theoria, 1986/87, no. 5/6, p. 368ff.

22. Anouk Barberousse and Pascal Ludwig, Les modles comme fictions, Philosophie, 68, 2000, p. 16-43.

23. Y. Bar-Hillel (ed.), Language and Information, Addison-Wesley, Reading MA, 1964

24. Y. Bar-Hillel, C. Gaifman, and E. Shamir, On categorial and phrase structure grammars, in: [23].

25. D. Barker-Plummer, D. Beaver, J. van Benthem, and P.S. di Luzio, Logic Unleashed: Language, Diagrams, and Computation, CSLI Publications, 2001.

26. D. Barker-Plummer, D. Beaver, J. van Benthem, and P.S. di Luzio, Proceedings of LLC8, CSLI Publications, to appear. !!!!

27. J. Barwise and J. Seligman, Information Flow: The logic of distributed systems, Cambridge University Press, 1997.

28. Barwise, Jon (ed.) Handbook of mathematical logic. With the cooperation of H. J. Keisler, K. Kunen, Y. N. Moschovakis, A.S. Troelstra, Studies in Logic and the Foundations of Mathematics, 90, Amsterdam, New York, Oxford, North-Holland Publishing, 1978. 
29. Jon Barwise, Information and Impossibilities, Notre Dame Journal of Formal Logic, 38, p.488-515.

30. S. Bauer, Metaframes, Typen und Modelle der modalen Prädikatenlogik, Dilplomarbeit, Humboldt-Universitäet zu Berlin, 2001.

31. S. Bauer and H. Wansing, Consequence, Counterparts and Substitution, preprint, 2001 (Heinrich.Wansing@mailbox.tu-dresden.de).

32. Karl Bayer and Joseph Lindauer, Lateinische Grammatik, Oldenburg, München, 1974.

33. G. Beer, Metric spaces on which continuous functions are uniformly continuous and Hausdorff distance, Procedings of the American Mathematical Society , 95, 1985, p. 653-658.

34. G. Beer, More about metric spaces on which continuous functions are uniformly continuous, Bulletin of the Australian Mathematical Society, 33, 1986, p. 397-406.

35. E. Bencivenga, Free Logics, in: [148, p. 373-426], p. 373-426.

36. E. Bencivenga, K. Lambert and R.K. Meyer, The Ineliminability of E! in Free Quantification Theory without Identity, Journal of Philosophical Logic, 11, 1982, p. 229-231.

37. J. van Benthem, Beyond Accessibility: Functional Models for Modal Logic, in: [382, p. 1$18]$.

38. J. van Benthem, Languange in Action, MIT Press, 1995.

39. Johan van Benthem, The logic of time, Reidel, Dordrecht, 1982.

40. Johan van Benthem and Alice ter Meulen (eds.), Handbook of logic and language, Amsterdam, North-Holland, 1997.

41. Johan van Benthem, Johan and Dag Westerstahl, Directions in generalized quantifier theory, Studia Logica, 55:3, p. 389-419, 1995.

42. Johan van Benthem, Logic in Games, electronic lecture notes, ILLC Amsterdam, preprint (http://turing.wins.uva.nl/ johan/Teaching/Phil.298.html), 2000 .

43. Heinrich Becker and Herrmann Walter, Formale Sprachen, Vieweg, Braunschweig, Wiesbaden, 1977.

44. C. Bicchieri, Rationality and Coordination, Cambridge Studies in Probability, Induction, and Decision Theory, Cambridge University Press, Cambridge, UK, 1993.

45. Steven Bird and Ewan Klein, Phonological Events, Journal of Linguistics, 29, 1990.

46. Max Black, Models and Archetypes, in: [483, p. 219-243], p. 219-243.

47. Ned Block and Robert C. Stalnaker, Conceptual Analysis, Dualism and the Explanatory Gap, The Philosophical Review, to appear.

48. Rens Bod, Beyond Grammar: An experience-based theory of language, CSLI Publications, Stanford, 1999

49. K. Bogers, H. van der Hulst, and M. Mous, The Representation of Suprasegmentals, Foris, Dordrecht, 1986.

50. Ludwig Boltzmann, Studien über das Gleichgewicht der lebendigen Kraft zwischen bewegten materiellen Punkten, in: [51, p. 49-96], 1968.

51. Ludwig Boltzmann, Wissenschaftlichen Abhandlungen, vol. I,

52. Ludwig Boltzmann, Studien über das Gleichgewicht der lebendigen Kraft zwischen bewegten materiellen Punkten, in: [51, p. 259-287], 1971.

53. Ludwig Boltzmann, Weitere Studien über das Gleichgewicht der lebendigen Kraft zwischen bewegten materiellen Punkten, in: [51, p. 316-402], 1972.

54. Emile Borel06, Sur les principes de la théorie cinétique des gaz, 1906.

55. Emile Borel, La mécanique statistique et l'irréversibilité, 1913.

56. G. Bouma and G. van Noord, CLIN IV, Papers from the fourth CLIN meeting, 1994.

57. P. Bouquet et al. (eds.), Proceedings of the Conference Context '01, Lecture Notes in Artificial Intelligence, Berlin, Springer, 2001. 
58. L. Bovens and S. Hartmann, Coherence, Belief Expansion and Bayesian Networks, preprint 2000, (arXiv.org e-Print archive; http://xxx.lanl.gov/abs/cs.AI/0003041)

59. L. Bovens and S. Hartmann, Bayesian Networks and the Problem of Unreliable Instruments, to appear in: Philosophy of Science (http://philsciarchive.pitt.edu/documents/disk0/00/00/00/95/index.html).

60. L. Bovens and S. Hartmann, Solving the Riddle of Coherence, preprint 2001.

61. L. Bovens and S. Hartmann, Belief Expansion, Contextual Fit and the Reliability of Information Sources, to appear in: [57].

62. L. Bovens and E.J. Olsson, Coherentism, Reliability and Bayesian Networks, in: Mind, 109, Issue 436, 2000, pp. 685-719.

63. R. Brandom, Making it Explicit, Cambridge MA, 1994

64. Walter Brainerd, Tree generating regular systems, Information and Control, 14,1969, p. 217-231.

65. Douglas K. Brown, Notions of compactness in weak subsystems of second order arithmetic, to appear.

66. Douglas K. Brown, Functional Analysis in Weak Subsystems of Second Order Arithmetic, Ph.D. thesis, The Pennsylvania State University, 1987.

67. Douglas K. Brown, Notions of closed subsets of a complete separable metric space in weak subsystems of second order arithmetic, in: [413, p. 39-50].

68. Douglas K. Brown and Stephen G. Simpson, The Baire category theorem in weak subsytems of second order arithmetic, Journal of Symbolic Logic, 58, 557-578, 1993.

69. J. Büchi, Weak second-order arithmetic and finite automata, Zeitschrift für Mathematische Logik und Grundlagen der Mathematik, 6, 1960, p. 66-92.

70. S. Burris and H.P. Sankappanavar, A course in universal algebra, Springer, Berlin, Heidelberg, New York, 1981.

71. S.R. Buss (ed.), Handbook of Proof Theory, Studies in Logic and the Foundations of Mathematics, 137, North-Holland, Amsterdam, 1998

72. W. Buszkowski, Proof Theory and Mathematical Linguistics, in: [40, ??].

73. Wojciech Buszkowski, Witold Marciszewski, and Johan van Benthem (eds.), Categorial grammar, Linguistic \& Literary Studies in Eastern Europe, 25, Amsterdam, 1988.

74. Wojciech Buszkowski, Three theories of categorial grammar, in: [73, p.57-84].

75. Stephan Brush, The Kind of Motion We Call Heat, North Holland, 1976.

76. Alex Byrne, Chalmers' Two-dimensionalism, preprint.

77. Mike, Calcagno, A Sign-Based Extension to the Lambek-Calculus for the Discontinuous Constituency, Bulletin of the IGPL, 3, 1995, p. 555-578.

78. A. Cantini, A theory of formal truth arithmetically equivalent to $I D_{1}$, Journal of Symbolic Logic, 55, 1990, p. 244-259.

79. Rudolf Carnap, Meaning and Necessity, University of Chicago Press, Chicago IL, 1947.

80. B. Carpenter, Type-Logical Semantics, Cambridge MA 1999.

81. Bob Carpenter and Carl J. Pollard. Inclusion, disjointness and choice: The logic of linguistic classification, Proc. 29th Annual Meeting of the ACL, 1991.

82. David Chalmers, The Conscious Mind, OUP, 1996.

83. David Chalmers, The Components of Content, preprint, http://www.u.arizona.edu / chalmers/papers/content.html

84. C. Chihara, The Worlds of Possibility. Modal Realism and the Semantics of Modal Predicate Logic, Clarendon Press, Oxford, 1998.

85. P. Cholak, M. Giusto, and J.L. Hirst, Free sets and reverse mathematics, in: [415].

86. Peter A. Cholak, Carl G. Jockusch, Jr., and Theodore A. Slaman, On the strength of Ramsey's theorem for pairs, Journal of Symbolic Logic, to appear. 
87. Noam Chomsky, Aspects of the Theory of Syntax, MIT Press, Cambridge MA, 1965.

88. N. Chomsky, Three models for the description of language, IRE Trans. on Information Theory IT-2, 3, 1956, p. 113-124.

89. Noam, Chomsky, Lecture Notes on Government and Binding, Foris, Dordrecht, 1981.

90. Noam, Chomsky, A Minimalist Program for Linguistic Theory, in: [195, p. 1-52].

91. Noam, Chomsky, The Minimalist Program, MIT Press, 1995.

92. Noam, Chomsky, Bare Phrase Structure, in: [466, p. 385-439].

93. Noam, Chomsky, Barriers, MIT Press, 1986.

94. Noam, Chomsky, On Formalization and Formal Linguistics, Natural Language and Linguistic Theory, 8, 1990, p. 143-147.

95. Noam Chomsky, Some Notes on Economy of Derivations, in: [142].

96. Noam, Chomsky, On Formalization and Formal Linguistics, Natural Lnaguage and Linguistic Theory, 8, 1990, p. 143-147.

97. Noam Chomsky, Some Notes on Economy of Derivations, in: [142].

98. Noam Chomsky, Syntactic Structures, Den Haag, Mouton, 1957.

99. Daniel Cohnitz, The Science of Fiction: Thought Experiments and Modal Epistemology, to appear.

100. Peter Coopmans, On Extraction from Adjuncts in VP, Proceedings of the WCCFL, 1988.

101. Thierry Coquand and Guo-Qiang Zhang, Sequents, frames, and completeness, in: [487].

102. B. Courcelle, Graph Rewriting: An Algebraic and Logic Approach, in: [295].

103. B. Courcelle, The Expression of Graph Properties and Graph Transformations in Monadic Second-Order Logic, in: [390].

104. R. Cowell, P. Dawid, S. Lauritzen and D. Spiegelhater, Probabilistic Networks and Expert Systems, New York, Springer, 1999

105. Max J. Cresswell, Logics and Languages, Methuen \& Co Ltd, London, 1973.

106. John N Crossley and Lloyd Humberstone, The Lgic of Actually, Reports on Mathematical Logic, 8, 1977, p. 11-29.

107. B.A. Davey and H.A. Priestley, Introduction to Lattices and Order, Cambridge University Press, Cambridge, 1991.

108. Donald Davidson, Gilbert Harman (eds.), Semantics of Natural Language, Reidel, Dordrecht, 1972.

109. Martin Davies and Lloyd Humberstone, Two Notions of Necessity, Philosophical Studies, 38, p. 1-30.

110. Dekker, Statistical Mechanics at the Turn of the Decade, ed. Cohen, 1970.

111. J. E. Doner, Tree acceptors and some of their applications, Journal of Computer and Systems Sciences, 4, 1970, p. 406-451.

112. J.R. Dorfman, An Introduction to Chaos in Non-Equilibrium Statistical Mechanics, Cambridge University Press, 1998.

113. K. Došen and P. Schroeder-Heister, Substructural logics, Oxford University Press, 1993.

114. F. Dretske, Knowledge and the Flow of Information, MIT Press, 1981, reprinted by CSLI Publications, 1999.

115. F. Dretske, Representational systems, in: [492].

116. Manfred Droste and Rüdiger Göbel. Non-deterministic information systems and their domains. Theoretical Computer Science, 75, 1990, p. 289-309.

117. W. Dubislav, Zur Unbegründbarkeit der Forderungsätze, Theoria, 3, 1937, p. 330-342.

118. J.M. Dunn and A. Gupta, Truth or Consequences, Kluwer, 1990.

119. J. Earman, Bayes or Bust??????, A Critical Examination of Bayesian Confirmation Theory, Cambridge, MA, MIT Press, 1992

120. J. Eatwell, M. Milgate, and P. Newman (eds.), The New Palgrave: A Dictionary of Economics, Macmillan Press, London, 1987. 
121. J. Eatwell, M. Milgate, and P. Newman (eds.), The New Palgrave: Game Theory, W. W. Norton, New York, 1989.

122. John Earman and Mikl ós Rédei, Why Ergodic Theory Does Not Explain the Success of Equilibrium Statistical Mechanics, British Journal for the Philosophy of Science, 47, 1996, p. 63-78.

123. Jan van Eijck and Hans Kamp, Representing discourse in context, in: [40, p. 179-238].

124. Jan van Eijck and H. Kamp, Representing discourse in context, in: [40, p. 179-237].

125. R. Engelking, General Topology, Heldermann-Verlag-Berlin, 1989.

126. Paul Ehrenfest and Tatjana Ehrenfeucht, The Conceptual Foundations of the Statistical Approach in Mechanics, Dover, 1913.

127. J. Etchemendy, The Concept of Logical Consequence, Havard University Press, 1990.

128. R. Fagin, Generalized first-order spectra and polynomial-time recognizable sets, in: [242].

129. S. Feferman et al. (eds.), Kurt Gödel. Collected Works. Volume I, Oxford University Press, New York, 1986.

130. S. Feferman, Reflecting on incompleteness, Journal of Symbolic Logic, 56, 1991, p. 1-49.

131. F. Fitch, A logical analysis of some value concepts, Journal of Symbolic Logic, 28, 1963, p. $135-142$.

132. B. Fitelson, The Plurality of Bayesian Measures of Confirmation and the Problem of Measure Sensitivity, Philosophy of Science, 63, p. 652-660.

133. M. Fitting and R.L. Mendelsohn, First-Order Modal Logic, Kluwer Academic Publishers, Dordrecht, 1998.

134. M. Fitting, First-Order Intensional Logic, preprint (http://comet.lehman.cuny.edu/fitting ), 2001.

135. M. Fitting, Types, Tableaus and Gödels God, preprint (http://comet. lehman. cuny. edu/fitting), 2001.

136. J. Fodor, The Language of Thought, NewYork, Crowell, 1975.

137. J. Fodor, A Theory of Content II, The Theory, in: [437, p.180-222].

138. J. Fodor, Connectionionism and the problem of systematicity (continued): Why Smolensky's solution still doesn't work, Cognition, 62, 1997, p. 109-119.

139. J. Fodor and J.J. Katz, The Structure of Language, Prentice-Wall, Englewood Cliffs, 1964.

140. J. Fodor and B. McLaughlin, Connectionionism and the problem of systematicity: Why Smolensky's solution doesn't work, Cognition, 35, 1990, p. 183-204.

141. J. Fodor and Z. Pylyshyn, Connectionism and cognitive architecture: A critical analysis, Cognition, 28, 1988, p. 3-71.

142. Robert Freidin, Principles and Parameters in Comparative Grammar, MIT Press, 1991.

143. Harvey Friedman, Fom:53:free sets/reverse math and fom:54:recursion theory/dynamics at http: //www.math.psu.edu/simpson/fom/.

144. H. Friedman, and R. Flagg, Epistemic and intuitionistic formal systems, Annals of Pure and Applied Logic, 32, 1986, p. 53-60.

145. H. Friedman, and M. Sheard, An axiomatic approach to self-referential truth, Annals of Pure and Applied Logic, 33, 1987, p. 1-21.

146. Harvey Friedman and Stephen G. Simpson, Issues and problems in reverse mathematics, Computability theory and its applications, Boulder CO 1999, Amer. Math. Soc., Providence, RI, 2000, p. 127-144.

147. Harvey Friedman, Stephen G. Simpson, and Xiaokang Yu, Periodic points in subsystems of second order arithmetic, Annals of Pure and Applied Logic, 62, 1993, p. 51-64.

148. D. Gabbay and F. Guenthner, Handbook of Philosophical Logic, Volume III: Alternatives to Classical Logic, Kluwer Academic Publishers, Dordrecht, 1986.

149. D. Gabbay and F. Guenthner, Handbook of Philosophical Logic: Extensions to Classical Logic, Kluwer Academic Publishers, Dordrecht, 1984. 
150. Gabby, Hogger and Robbinson (eds.), Handbook of Logic in Artificial Intelligence and Logic Programming, vol. 3, Oxford University Press, 1994.

151. Dov Gabbay and Franz Guenthner (eds.), Handbook of philosophical logic. Volume I: Elements of classical logic, Synthese Library, 164, Dordrecht, Reidel, 1983

152. Dov Gabbay and Franz Guenthner (eds.), Handbook of philosophical logic, Volume II: Extensions of classical logic, Synthese Library, 165, Dordrecht, Reidel, 1984.

153. Dov Gabbay and Franz Guenthner (eds.), Handbook of philosophical logic. Volume III: Alternatives to classical logic, Snythese Library, 166, Dordrecht, Reidel, 1986.

154. Dov Gabbay and Franz Guenthner (eds.), Handbook of philosophical logic. Volume IV: Topics in the philosophy of language, Synthese Library, 167, Dordrecht, Reidel, 1989.

155. Dov M. Gabbay, Christopher J. Hogger, J.A. Robinson, and Jörg Siekmann, Handbook of logic in artificial intelligence and logic programming. Volume 1: Logical foundations, Oxford, Clarendon Pres, 1993.

156. Dov M. Gabbay, Christopher J. Hogger, J.A. Robinson, ?? Handbook of logic in artificial intelligence and logic programming. Volume 2: ??, Oxford, Clarendon Pres, 1993.

157. Dov M. Gabbay, C.J. Hogger, J.A. Robinson, and D. Nute (eds.), Handbook of logic in artificial intelligence and logic programming. Volume 3: Nonmonotonic reasoning and uncertain reasoning, Oxford, Clarendon Press, 1994.

158. Dov M. Gabbay, C.J. Hogger, J.A. Robinson (eds.) Handbook of logic in artificial intelligence and logic programming. Volume 4: Epistemic and temporal reasoning, Oxford, Clarendon Press, 1995.

159. Dov M. Gabbay, C.J. Hogger, J.A. Robinson (eds.) Handbook of logic in artificial intelligence and logic programming. Volume 5, Logic programming, Oxford: Clarendon Press, 1998.

160. Dov M. Gabbay, Labelled deductive systems. Volume 1, Oxford Logic Guides, 33, Oxford, Clarendon Press, 1996.

161. Giovanni Gallavotti, Chaotic Dynamics, Fluctuations, nonequilibrium ensembles, Chaos, 8, 1998, p. 384-392.

162. L.T.F. Gamut, Logic, language and meaning, Volume 1: Introduction to Logic, Chicago University Press, Chicago, 1991.

163. L.T.F. Gamut, Logic, language and meaning, Volume 2: Intensional Logic and Logical Grammar, Chicago University Press, Chicago, 1991.

164. J.W. Garson, Quantification in Modal Logic, in: [149, p. 249-307].

165. J.W. Garson, Applications of Free Logic to Quantified Intensional Logic, in: [281, p. 111144].

166. Gerald, Gazdar, Ewan Klein, Geoffrey Pullum, and Ivan Sag, Generalized Phrase Structure Grammar, Blackwell, Oxford, 1985.

167. Gerald Gazdar, Geoffrey Pullum, R. Carpenter, E.H. Klein, T.E. Hukari, and R.D. Levine, Category Structures, Journal of Computational Linguistics, 14:1, 1998, p. 114.

168. F. Gécseg and M. Steinby, Tree Languages, in: [393].

169. T. van Gelder, The dynamical hypothesis in cognitive science, Behavioral and Brain Sciences, 21, 1998, p. 1-14.

170. J. Gerbrandy, M. Marx, M. de Rijke and Y. Venema, JFAK. Essays Dedicated to Johan van Benthem on the Occasion of his 50th Birthday, Amsterdam University Press, 1999.

171. G. Germano, Mathematische Begriffe in Standardtheorien, Archiv für Mathematische Logik, 13, 1970, p. 22-38.

172. S. Ghilardi, Incompleteness Results in Kripke Semantics, Journal of Symbolic Logic, 56, 1991, p. 516-538. 
173. S. Ghilardi, Quantified Extensions of Canonical Propositional Intermediate Logics, Studia Logica 51 (1992), p. 195-214.

174. L. Giacardi, E. Gallo and F. Pastrone (eds.), Conferenze e Seminari 1993-1994, Associazione Subalpina Mathesis e Seminario di Storia delle Matematiche "T. Viola", Torino, 1994, pp. 201-211.

175. Gibbs, Elementary Principles in Statistical Mechanics, Dover (1965), 1902. ????

176. G. Gigerenzer and K. Hug, Domain-specific reasoning: Social contracts, cheating, and perspective change, Cognition, 43, 1992, p. 127-171.

177. Jonathan Ginzburg, Lawrence S. Moss, and Maarten de Rijke, eds., Logic, Language, and Computation, Vol. 2, CSLI, 1999.

178. Günther Grewendorf, Fritz Hamm, Wolfgang Sternefeld, Sprachliches Wissen, Eine Einführung in moderne Theorien der grammatischen Beschreibung, ... 1987 [suhrkamp taschenbuch wissenschaft 695]

179. Gisbert Fanselow and Sascha Felix, Sprachtheorie, Bd. 2: Die Rektions- und Bindungstheorie, UTB No. 1441/2, Tübingen, 1987.

180. Bas van Fraassen, The Scientific Image, Oxford University Press, 1980.

181. Mariagnese Giusto, Topologia, Analisi e Reverse Mathematics, Ph.D. thesis, Università di Torino, 1998.

182. Mariagnese Giusto and Alberto Marcone, Lebesgue numbers and Atsuji spaces in subsystems of second order arithmetic, Arch. Math. Logic, 37, 1998, p. 343-362.

183. K. Gödel, An interpretation of the intuitionistic calculus, in: [129, p. 300-303].

184. R. Goldblatt, Logics of Time and Computation, Studies in Logic, Language and Information, CSLI, Standford, 1992.

185. George, Grätzer, Lattice Theory, Freeman, San Fransisco, 1971.

186. George Grätzer, Universal Algebra, Springer Verlag, Berlin, Heidelberg, New York, 1979.

187. R. Greenlaw, H.J. Hoover and W.L. Ruzzo, Limits to Parallel Computation: $P$ Completeness Theory, Oxford University Press, 1995.

188. P. Grim, Operators in the paradox of the knower, Synthese, 94, 1993, p. 409-428.

189. A. Gupta, and N. Belnap, The Revision Theory of Truth, The MIT Press, Cambridge, MA, 1993.

190. Y.M. Guttmann, The Concept of Probability in Statistical Physics, Cambridge University Press, 1999.

191. Liliane, Haegaman, Introduction to Government and Binding Theory, Blackwell, Oxford, 1991.

192. V.Halbach, A system of complete and consistent truth, Notre Dame Journal of Formal Logic, 35, 1994, p. 311-327.

193. V. Halbach, H. Leitgeb, and P. Welch, Possible worlds semantics for predicates of sentences, in preparation.

194. V. Halbach and L. Horsten, Principles of Truth, Proceedings of a conference on Truth, Necessity and Provability, held in Leuven (Belgium), November 1999. to appear.

195. K. Hale and S.J. Keyser, The View from Building 20: Essays in Honour of Sylvain Bromberger, MIT Press, 1993.

196. J. Halpern (ed.), Theoretical Aspects of Reasoning about Knowledge: Proceedings of the 1986 conference, Morgan Kaufman, 1986.

197. L. A. Harrington, M. Morley, A. Ščedrov, and S. G. Simpson (eds.), Harvey Friedman research on the foundations of mathematics, Studies in Logic and the Foundations of Mathematics, North-Holland, 1985.

198. Michael, A. Harrioson, Introduction to Formal Language Theory, Addison-Wesley, 1978.

199. S. Hartmann and L. Bovens, The Variety-of-Evidence Thesis and the Reliability of Instruments: A Bayesian-Network Approach, preprint 2001, (http://philsciarchive.pitt.edu/documents/disk0/00/00/02/35/index.html) 
200. Allen Hazan, Counterpart-Theoretic Semantics for Modal Logic, The Journal of Philosophy, 76, 1979, p. 319-338.

201. Allen Hazen, Expressive Completeness in Modal Languages, Journal of Philosophical Logic, 5, 1976, p. 25-46.

202. G. Hellman, Review of Martin and Woodruff 1975, Kripke 1975, Gupta 1982 and Herzberger 1982, Journal of Symbolic Logic, 50, 1985, p. 1068-1071.

203. H. Hendriks, Studied Flexibility, PhD thesis, University AMsterdam, 1993.

204. J. Higginbotham and F. Pianesi (eds.), Speaking about events. Oxford U. Press, 2000.

205. J. Hintikka, Existential Presuppositions and Their Elimination, in: [482, p. 23-44].

206. Jaakko Hintikka and Gabriel Sandu, On the methodology of linguistics: a case study, Blackwell, Oxford, 1991.

207. Jaakko Hintikka and Gabriel Sandu, Game-theoretical semantics, in: [40, p. 361-410].

208. J. Hillas, and E. Kohlberg, Foundations of Strategic Equilibrium, in: [15].

209. R. Hilpinen (ed.), New Essays in Deontic Logic, Reidel, Dordrecht, 1981

210. Jeffry L. Hirst, Combinatorics in Subsystems of Second Order Arithmetic, Ph.D. thesis, The Pennsylvania State University, 1987.

211. Jeffry L. Hirst, Derived sequences and reverse mathematics, Mathematical Logic Quarterly, 39, 1993, p. 447-453.

212. Jeffry L. Hirst, A survey of the reverse mathematics of ordinal arithmetic, in: [415], 2000.

213. Harold Hodes, Some Theorems on the Expressive Limitations of Modal Languages, Journal of Philosophical Logic, 13, 1984, p. 13-26.

214. J.E. Hopcroft, R. Motwani, and J.D. Ullman, Introduction to Automata Theory, Languages, and Computation, Addison-Wesley, 2000.

215. T. Torgan and J. Tienson, Connectionism and the Philosophy of Psychology, MIT Press, Cambridge MA, 1996.

216. L. Horsten, A Kripkean approach to unknowability and truth, Notre Dame Journal of Formal Logic, 39, 1998, p. 389-405.

217. L. Horsten, Axiomatic treatments of informal provability as a predicate, to appear in: [194].

218. C. Howson and P. Urbach, Scientific Reasoning - The Bayesian Approach, 2nd ed., Chicago, Open Court, 1993.

219. A. James Humphreys, On the Necessary Use of Strong Set Existence Axioms in Analysis and Functional Analysis, Ph.D. thesis, The Pennsylvania State University, 1996.

220. A. James Humphreys, Did Cantor need Set Theory?, to appear.

221. G. Hughes and M. Cresswell, A Companion to Modal Logic, Methuen, 1984.

222. G.E. Hudges and M.J. Cresswell, A New Introduction to Modal Logic, Routledge, London, 1996.

223. Harry van der Hulst, Syllable Structure and Stress in Dutch, Foris, Dordrecht, 1984.

224. Harry van den Hulst N. Smith, On neutral vowels, in: [49, p.233-279].

225. Lloyd Humberstone, Scope and Subjunctivity, Philosophia, 12, 1982, p. 99-126.

226. Kiyoshi Iseki, On the property of Lebesgue in Uniform Spaces I-V, Procedings of the Japan Academy, 31, 1955, pp. 220-221, 270-271, 441-442, 524-525, 618-619.

227. G. Jaeger, On the generative capacity of multi-modal Categorial Grammars, preprint, Institute for Research in Cognitive Science, University of Pennsylvania, Philadelphia, 1998.

228. Theo M.V. Jannsen Foundations and Applications of Montague Grammar, PhD thesis, Mathematical institute, University of Amsterdam, 1983.

229. R. Jakobson, Structure of Language and its Mathematical Aspects, American Mathematical Society, 1961

230. Carl G. Jockusch, Jr., private communication.

231. J. Jørgensen, Imperatives and logic. Erkenntnis, 7, 1937-8, p. 288-296.

232. Adolf Kaegi, Griechische Schulgrammatik, Weidemann Verlag. 
233. H. Kamp and U. Reyle, From Discourse to Logic, Dordrecht 1993

234. H. Kamp and U. Reyle, A calculus for first-order discourse representation structures, Journal of Logic, Language and Information 5 (1996), p. 297-348.

235. M. Kanazawa, The Lambek Calculus Enriched With Additional Connectives, Journal of Logic, Language, and Information, 1:2, 1992, p.141-171.

236. M. Kanazawa, Lambek Calculus: Recognizing Power and Complexity, in: [170].

237. M. Kanazawa, Learnable Classes of Categorial Grammars, CSLI Publications, 1998.

238. Y. Kakuda, A mathematical description of GDT: A marriage of Yoshikawa's GDT and Barwise-Seligman's theory of information flow, unpublished paper given at GDT '99 Workshop, Cambridge, 1999

239. Y. Kakuda and M. Kikuchi, Abstract Design Theory, Annals of the Japan Association for Philosophy of Science, to appear.

240. D. Kaplan, How to Russell a Frege-Church, The Journal of Philosophy, 72, 1975, p. 716729.

241. D. Kaplan and R. Montague, A paradox regained, Notre Dame Journal of Formal Logic, 1, 1960, p. 79-90.

242. R.M. Karp, Complexity of Computation, 1974.

243. R.T. Kasper and W.C. Rounds, The Logic of Unification in Grammar, Linguistics and Philosophy, 13, 1990, p. 35-58.

244. Jonathan Kaye, Jean Lowenstamm, and Jean-Roger Vergnaud, Konstituentenstruktur und Rektion in der Phonologie, in: [369, p. 31-75].

245. K. Kaysen, A Revolution of Economic Theory?, Review of Economic Studies, 14, 1, p. 1946-1947, 1-15.

246. Edward L. Keeman and Leonard M. Faltz, Boolean Semantics for Natural Language, Synthese Language Library, 23, Reidel, Dordrecht, 1985.

247. Edward L. Keenan and Dag Westerstahl, Generalized Quantifiers in Linguistics and Logic, in: [40, p. 838-893]

248. J. Kim, Mechanism, purpose and explanatory exclusion, in: [491].

249. Edward Klima, Negation in English, in: [139].

250. D. König, Theorie der Endlichen und Unendlichen Graphen, Akademische Verlagsgesellschaft, Leipzig, 1936, reprinted by Chelsea, New York, 1950.

251. Jaklin Kornfilt, Turkish, Routledge, London, 1997.

252. Jan Koster and Eric Reuland, Long-Distance Anaphora, Cambridge University Press, Cambridge, 1991.

253. Jan Koster, Domains and Dynasties: the Radical Autonomy of Syntax, Foris, Dordrecht, 1986.

254. M. Kracht et. al., Advances in Modal Logic, Volume I, CSLI Publications, Standford, 1998.

255. M. Kracht, Tools and Techniques in Modal Logic, Studies in Logic and the Foundations of Mathematics, 142, Elsevier Science Publishers, Amsterdam, 1999.

256. M. Kracht and O. Kutz, The Semantics of Modal Predicate Logic I. Counterpart Frames, in: [477].

257. M. Kracht and O. Kutz, The Semantics of Modal Predicate Logic II. Modal Individuals Revisited, preprint (http://www.informatik.uni-leipzig.de/ kutz, 2001.

258. Marcus Kracht, The Theory of Syntactic Domains, Dept. of Philosophy, Rijksuniversiteit Utrecht, Logic Group Preprint Series No. 75, preprint, 1992.

259. Marcus Kracht, Mathematical Aspects of Command Relations, Proceedings of the EACL 93, 1993.

260. Marcus Kracht, Nearness and Syntactic Influence Spheres, preprint, 1993. 
261. Syntactic Codes and Grammar Refinement, Journal of Logic, Language and Information, 1995.

262. Marcus Kracht, On Reducing Principles to Rules, Free University Berlin, preprint, 1996.

263. Marcus Kracht, Inessential Features, in: [378]

264. Markus Kracht, Tools and Techniques in Modal Logic, Studies in Logic, Elsevier, Amsterdam, 142, 1999.

265. Marcus Kracht, Constraints on Derivations, Department of Mathematics, FU Berlin, preprint, 2001.

266. Marcus Kracht, Logic and Syntax - A Personal Perspective, in: [268, p. 337-366]

267. Marcus Kracht, Tools and Techniques in Modal Logic, Studies in Logic, Amsterdam, Elsevier, 142, 1999.

268. Michael Zahkarayaschev, Krister Segerberg, Maarten de Rijke, and Heinrich Wansing, Advances in Modal Logic, 2, CSLI, Stanford, 2001.

269. S.A. Kripke, A Puzzle About Belief, in: [311, p. 239-283].

270. S. Kripke, Outline of a theory of truth, 1975, reprinted in: [313, p.53-81].

271. Saul A. Kripke, Naming and necessity. in: [108, p.253-355].

272. Saul Kripke, Outline of a Theory of Truth, Journal of Philosophical Logic, 72, 1975, p. $690-716$.

273. Saul Kripke, Naming and Necessity, Havard, Cambridge MA, 1980.

274. Krister Segerberg, Two-dimensional Modal Logic, Journal of Philosophical Logic, 2, p. 77-96.

275. Joseph B. Kruskal, Well-quasi-ordering, the tree theorem and Vazsonyi's conjecture, Trans. Amer. Math. Soc., 95, 1960, p. 210-225.

276. K. Kuratowski and A. Mostowski, Set Theory with an Introduction to Descriptive Set Theory, Amsterdam, North Holland, 1976

277. O. Kutz, Kripke-Typ Semantiken für die modale Prädikatenlogik, Diplomarbeit, Humboldt-Universität zu Berlin, 2000.

278. J. Lambek, Deductive Systems and Categories I, Mathematical Systems Theory, 2:4, 1968, p. 287-318.

279. K. Lambert, Free Logics: Their Foundations, Character, and Some Applications Thereof, Academia Verlag, Sankt Augustin, 1997.

280. J. Lambek, Logic without structural rules (another look at cut elimination), in: [113].

281. K. Lambert, Philosophical Applications of Free Logic, Oxford University Press, New York, Oxford, 1991.

282. J. Lambek, On the Calculus of Syntactic Types, in: [229].

283. J. Lambert, The Mathematics of Sentence Structure, American Mathematical Monthly, 65, 1958, p. 154-169.

284. K. Lambert, Philosophical Problems in Logic. Some Recent Developments, Reidel, Dordrecht, 1970.

285. O. Landford, Springer Notes in Physics 38:1, Springer, 1975.

286. O. Landford, The Hard Sphere Gas in the Boltzmann-Grad Limit, Physica, 106A, 1981, p. $70-76$.

287. A. Lascarides and N. Asher, Temporal interpretation, discourse relations and commonsense entailment, Linguistics and Philosophy, 16, p. 437-594, 1993.

288. Howard Lasnik, Remarks on Coreference, Linguistic Analysis, 2, 1976, p. 1-22.

289. Rogor Lass, Phonology. An introduction to basic concepts, Cambridge University Press, Cambridge, 1984.

290. Joel L. Lebowith, E. Presutti, and H. Spohn, Microscopic Models of Hydrodynamics Behavior, Journal of Statistical Physics, 51, 1988, p. 841-862. 
291. Joel L. Lebowitz, Macroscopic Laws, Microscopic Dynamics, Time's Arrow and Boltzmann's Entropy, Physica A, 1993, p. 1-27.

292. Joel L. Lebowitz, Boltzmann's Entropy and Time's Arrow, Physics Today, 1993, p. 3238.

293. Joel L. Lebowitz, Microscopic Origins of Irreversible Macroscopic Behavior, STATPHYS, 1998.

294. H. Leitgeb and L. Horsten, No future, to appear in Journal of Philosophical Logic.

295. J. van Leeuwen, Handbook of Theoretical Computer Science, B, Elsevier, 1990.

296. J. van Leeuwen, Individuals and Sortal Concepts. An Essay in Logical Metaphysics, PhD thesis, University of Amsterdam, 1991.

297. Willem P. Levelt, Speaking. From Intention to Articulation, MIT Press, Cambridge MA, 2, 1991.

298. D. Lewis, Counterpart Theory and Quantified Modal Logic, Journal of Philosophy 65 (1968), p. 113-126, reprinted in: [302] and [299].

299. D. Lewis, Philosophical Papers 1, Oxford, 1983.

300. D. Lewis, On the Plurality of Worlds, Oxford, Blackwell, 1986.

301. Benedikt Löwe, The Formal Sciences: Their Scope, Their Foundations, and Their Unity, to appear in Synthese.

302. M.J. Loux, The Possible and the Actual, Ithaca, 1979.

303. D. Lightfoot and A. Weinberg, Barriers (Review Article), Language, 64, 1998.

304. D. Luce, and H. Raiffa, Games and Decisions, John Wiley and Sons, New York, 1957.

305. C. Macdonald and G. Macdonald, Connectionism, Blackwell, Cambridge MA, 1995, p. 1995.

306. D. Makinson, General Patterns in Nonmonotonic Reasoning, in: [150], p 35-110.

307. D. Makinson, On a fundamental problem of deontic logic, In: [320], p. 29-53.

308. D. Makinson and L. van der Torre, Input/output logics, J. Philosophical Logic 29, 2000, p. 383-408.

309. D. Makinson and L. van der Torre, Constraints for input/output logics, J. Philosophical Logic 30(2), 2001, p. 155-185.

310. Alberto Marcone, Quali assiomi per la matematica? Dall'assioma delle parallele alla reverse mathematics, in: [174].

311. A. Margalit, Meaning and Use, D. Reidel Publishing Co., Dordrecht, Boston, 1979.

312. Maria R. Manzini, Locality - A Theory and Some of Its Empirical Consequences, Linguistic Inquiry Monographs, 19, MIT Press, 1992.

313. R.L. Martin (ed.), Recent Essays on Truth and the Liar Paradox, Oxford University Press, 1984.

314. James Clerk Maxwell, Illustrations of the Dynamical Theory of Gases, Philosophical Magazine, 19-20, 1860, p. 19-32, p. 21-37, (reprinted in: [345, p. 377-409]).

315. James Clerk Maxwell, On the Dynamical Theory of Gases, Philosophical Transactions of the Royal Society of London, 157, 1867, p. 49-88, (reprinted in: [346, p. 26-78]).

316. James Clerk Maxwell, On Boltzmann's Theorem on the Average Distribution of Energy in a System of Material Points, Cambridge Philosophical Society's Transations, 12 1879, reprinted in: [346, p. 713-741].

317. E. F. McClennen, Rationality and Dynamic Choice. Foundational Explorations, Cambridge University Press, Cambridge, UK, 1990.

318. V. McGee, How truthlike can a predicate be? A negative result, Journal of Philosophical Logic, 14, 1985, p. 399-410.

319. R.N. McKenzie, G.F. McNulty, and W.F. Taylor, Algebras, lattices and varieties, 1, Wadsworth and Brooks, Monterey CA, 1987. 
320. P. McNamara and H. Prakken (eds.), Norms, Logics and Information Systems, New Studies in Deontic Logic and Computer Science, Frontiers in Artificial Intelligence and Applications, Volume 49, 1999.

321. Robert McNaughton, Parenthesis Grammars, Journal of the Association for Computing Machinery, 14, 1967, p. 490-500.

322. A. ter Meulen Representing Time in Natural Language. The dynamic interpretation of tense and aspect, Cambridge MA, Bradford Books, MIT Press, 1995.

323. A. ter Meulen, Perspektiven in die logische Semantik, in: [458].

324. A. ter Meulen, As time goes by ... Representing ordinary English reasoning in time about time, J50 Festschrift CD for J. van Benthem's 50th birthday. ILLC, UvA, 1999.

325. A. ter Meulen, Chronoscopes: dynamic tools for temporal reasoning, in: [204]

326. J.J. Meyer and R.J. Wieringa (eds.), Deontic Logic in Computer Science, Wiley, New York, 1993

327. Ph.H. Miller, Strong Generative Capacity, CSLI Publications, to appear.

328. R. Montague, Syntactical treatments of modality, with corollaries on reflection principles and finite axiomatizability, [1963], reprinted in: [329, p. 286-302].

329. R. Montague, Formal Philosophy: Selected Papers of Richard Montague, Yale University Press, 1974.

330. Richard Montague, Formal philosophy. New Haven, Yale University Press, 1974.

331. J.D. Moore and K. Stenning, Proceedings of the Twenty-Third Annual Conference of the Cognitive Science Society, London, Lawrence Erlbaum Associates, 2001.

332. M. Moortgat, Proceedings of the 3rd International Conference on Logical Aspects of Computational Linguistics, Springer, 2001.

333. Michael Moortgat, Categorial Type Logics, in: [40, p. 93-177].

334. S. Morgenbesser (ed.), Philosophy of science today, Basic Books, 1967.

335. L.S. Moss and H.-J. Tiede, Course notes for Mathematics from Language, Indiana University, 1999.

336. L. Morgenstern, A first-order theory of planning, knowledge and action, in: [196].

337. G.V. Morrill, Type Logical Grammar, Kluwer, 1994.

338. Laurence Moss and Jeremy Seligman, Situation Theory, in: [40, p. 239-309].

339. C.U. Moulines, Structuralism: The Basic Ideas, in: [19].

340. Alan B. Munn, Topics in the Syntax and Semantics of Coordinate Structures, $\mathrm{PhD}$ thesis, University of Maryland, 1993.

341. R. Muskens, Johan van Benthem, Albert Visser, Dynamics, in: [40, p. 589-648].

342. J. Myhill, Some remarks on the notion of proof, Journal of Philosophy, 57, 1960, p. 461471.

343. R. Neapolitan, Probabilistic Reasoning in Expert Systems: Theory and Algorithms, New York, Wiley, 1990.

344. K.G. Niebergal, Simultane objektsprachliche Axiomatisierung von Notwendigkeits- und Beweisbarkeitsprädikaten, Hausarbeit zur Erlangung des Magistergrades an der LudwigMaximilians-Universität München, 1991.

345. W.D. Niven (ed.), The Scientific Papers of James Clerk Maxwell (1890), volume I, New York, Dover, 1961

346. W.D. Niven (ed.), The Scientific Papers of James Clerk Maxwell (1890), volume II, New York, Dover, 1961

347. G. Nunberg, I. Sag, and T. Wasow, Idioms, Language, 70, 1994, p. 491-538.

348. Rainer Osswald, Semantics for attribute-value theories, in: [488].

349. Rainer Osswald, Classifying classification, in: [489].

350. B. Partee, A. ter Meulen, and R. Wall, Mathematical Methods in Linguistics, Kluwer Academic Publishers, Dordrecht, 1990. 
351. J. Pearl, Probabilistic Reasoning in Intelligent Systems, San Mateo, Cal, Morgan Kaufmann, 1988.

352. J. Pearl, Causation: Models, Reasoning, and Inference, Cambridge, Camberidge University Press, 2000

353. M. Pentus, Product-free Lambek calculus and context-free grammars, The Journal of Symbolic Logic, 62:2, 1997, p. 648-660.

354. F. Pereira and D.H.D. Warren, Parsing as Deduction, Proceedings of the 21st Annual Meeting of the Association for Computational Linguistics, 1983.

355. F. Pereira and D.H.D. Warren, Definite Clause Grammars for Language Analysis, Artificial Intelligence, 13, 1980, p. 231-278.

356. John Perry, Knowledge, Possibility, and Consciousness, MIT Press, 2001.

357. M. Plancherel13, Beweis der Unmöglichkeit ergodischer mechanischer Systeme, Annalen der Physik, 42, p. 1061-1063, 1913.

358. Jan von Plato, Creating Modern Probability, Cambridge University Press, 1994.

359. K. P. Podewski and K. Steffens, Injective choice functions for countable families, Journal of Combinatorial Theory, Series B, 21, 1976, p. 40-46.

360. R. Pöschel and L. Kaluznin, Funktionen- und Relationenalgebren, Birkhäuser, 1979.

361. Krisztina Polgárdi, Vowel Harmony, An Account in Terms of Government and Optimality, $\mathrm{PhD}$ thesis, Holland Institute of Generative Linguistics, 1998.

362. Thomas W. Polger, Zombies Explained, in: [392].

363. Carl Pollard and Ivan Sag, Head-Driven Phrase Structure Grammar, The University of Chicago Press, Chicago, 1994.

364. Geoffrey Pullum, Formal Linguistics meets the Boojum, Natural Language and Linguistic Theory, 7, 1987, p.137-143.

365. L. Plos et al. (eds.), Applied Logic: How, What and Why, Dordrecht, Kluwer Publishers, 1995.

366. D. Poole, A logical framework for default reasoning, Artificial Intelligence 36, 1988, p. 27-47.

367. Post, The Two-Valued Iterative Systems of Mathematical Logic, Annals of Mathematical Studies, Princeton U.P., 1941.

368. H. Prakken and M. Sergot, Contrary-to-duty obligations, Studia Logica 57, 91-115.

369. Martin Prinzhorn, Phonologie, Westdeutscher Verlag, Opladen, 1989.

370. P. Pudlák, The Length of Proofs, in: [71].

371. W. V. Quine, Ontological relativity, in: [490].

372. W. V. Quine, From Stimulus to Science, Harvard University Press, 1995.

373. W. Reinhardt, Some remarks on extending and interpreting theories with a partial predicate for truth, Journal of Philosophical Logic, 15, 1986, p. 219-256.

374. W. Reinhardt, Epistemic theories and the interpretation of Gödel's incompleteness theorems, Journal of Philosophical Logic, 15, 1986, p. 427-474.

375. Tanya Reinhart, Definite NP-Anaphora and C-command Domains, Linguistic Inquiry, 12, 1981, p. 605-635.

376. R. Reiter, A logic for default reasoning, Artificial Intelligence 13, 1980, p. 81-132.

377. G. Restall, An Introduction to Substructural Logics, Routledge, 2000.

378. Christian Retoré, Proceedings of LACL 96, Lecture Notes in Artificial Intelligence, 1328, Springer, Heidelberg, 1997.

379. Christian Retoré, Proceedings of LACL 96, Lecture Notes in Artificial Intelligence, 1328, Springer, Heidelberg, 1997.

380. Christian Retoré François Lamarche, Proof nets for the Lambek calculus - an overview, in: $[3, ?]$ 
381. H. van Riemsdijk and E. Williams, Introduction to the Theory of Grammar, MIT Press, 1986.

382. M. de Rijke, Diamonds and Defaults: Studies in Pure and Applied Intensional Logic, Kluwer Academic Publishers, Dordrecht, 1993.

383. D.C. Rine (ed.), Computer Science and Multiple-Valued Logic: Theory and Applications, Noth-Holland, 1984.

384. Sven E. Ristad, Computational Structure of GPSG Models, Linguistics and Philosophy, 13, 1990, p. 521-587.

385. Luigi Rizzi, Relativized Minimality, MIT Press, Boston MA, 1990.

386. D. Roorda, Resource Logics: Proof-theoretical Investigations, PhD. thesis, University of Amsterdam, 1991.

387. D. Roorda, Proof Nets for Lambek Calculus, Journal of Logic and Computation, 2:2, 1992, p. 211-231.

388. G. Rosen, Modal Fictionalism, Mind, 99, 1990, p. 327-354.

389. Ivo Rosenberg, Completeness properties of multiple-valued logic algebras, in: [383, p. 150-192].

390. G. Rosenberg, Handbook of Graph Grammars and Computing by Graph Transformation. Vol. I: Foundations, World Scientific, 1997.

391. A. Rosenthal, Beweis der Unmöglichkeit ergodischer Gassysteme, Annalen der Physik, 42, p. 796-806, 1913.

392. Donn Ross, Andrew Brook, and David Thompson, Dennett's Philosophy. A Comprehensive Assessment.

393. G. Rozenberg and A. Salomaa, Handbook of Formal Languanges, 3, Springer, 1997.

394. J. Rowers, A Descriptive Approach to Language Theoretic Complexity, CSLI Publication, 1998.

395. James Rogors, Studies in the Logic of Trees with Applications to Grammar Formalisms, $\mathrm{PhD}$ thesis, Department of Computer and Information Sciences, University of Delaware, 1994.

396. James Rogers, What Does a Grammar Formalism Say About a Language?, Institute for Research in Cognitive Science, University of Pennsylvania, preprint, 1995

397. David Ruelle, Statistical Mechanics. Rigorous Results, W.A. Benjamin, 1969.

398. D. Ruelle and Ya. Sinai, From Dynamical Systems to Statistical Mechanics and Back, Physica, 140A, 1986, p. 1-8, 1986.

399. Ivan A. Sag and Thomas Wasow, Syntactic Theory: A Formal Introduction, CSLI, 1999.

400. Victor Sanchez, Valencia, 2001, Natural Logic, to appear with MIT Press

401. A. Salomaa and G. Rozenberg, Handbook of Formal Languages, Volume 1, Springer, Berlin, 1997.

402. T. Sata, E. Warman (eds.), Man-machine Communication in CAD/CAM, North-Holland, 1981.

403. T.B. Schillen and P. König, Binding by temporal structure in multiple feature domains of an oscillatory neuronal network, Biological Cybernatics, 70, 1994, p. 397-405.

404. D. Scott, Advice on Modal Logic, in: [284, p. 143-174], p. 143-174.

405. J. Seligman and L. Moss, Situation Theory. in: [40, 239-309].

406. J. Seligman and A. ter Meulen, Dynamic aspect trees, in: [365, p. 287-320].

407. Peter Sells, Lectures on Contemporary Syntactic Theories, CSLI Lecture Notes, 3, 1985.

408. S. Shapiro (ed.), Intensional Mathematics, North-Holland, 1985

409. S. Shapiro, Epistemic and intuitionistic arithmetic, in: [408, p. 11-46].

410. S. Shieber, Evidence Against the Context-freeness of Natural Language, Linguistics and Philosophy, 8, 1985, p. 333-343. 
411. S.M. Shieber, Y. Schabes and F.C.N. Pereira, Principles and Implementation of Deductive Parsing, Journal of Logic Programming, 24:1-2, 1995, p. 3-36.

412. H. Shirasu, Duality in Superintuitionistic and Modal Predicate Logics, in: [254, p. $223-$ 236].

413. W. Sieg (ed.), Logic and Computation, Contemporary Mathematics, American Mathematical Society, 1990.

414. P.M. Simmons, On Being Spread Out in Time: Temporal Parts and the Problem of Change, in: [431].

415. S. G. Simpson (ed.), Reverse Mathematics 2001, in preparation.

416. S.G. Simpson, K. Tanaka, and T. Yamazaki, Some conservation results on Weak König's Lemma, in preparation, 2001.

417. Stephen G. Simpson, Subsystems of $Z_{2}$ and reverse mathematics, in: [443, p. 434-448].

418. Stephen G. Simpson, Nonprovability of certain combinatorial properties of finite trees, in: [197, p. 87-117].

419. Stephen G. Simpson, Partial realizations of Hilbert's program, Journal of Symbolic Logic 53 (1988), 349-363.

420. Stephen G. Simpson, On the strength of König's duality theorem for countable bipartite graphs, Journal of Symbolic Logic 59 (1994), 113-123.

421. Stephen G. Simpson, Subsystems of Second Order Arithmetic, Perspectives in Mathematical Logic, Springer-Verlag, 1999.

422. Stephen G. Simpson and Rick L. Smith, Factorization of polynomials and $\Sigma_{1}^{0}$ induction, Annals of Pure and Applied Logic, 31, 1986, p. 289-306.

423. Ya. Sinai, Introduction to Ergodic Theory, Princeton University Press, 1976.

424. W. Singer and C.M. Gray, Visual feature integration and the temporal correlation hypothesis, Annual Review of Neuroscience, 18, 1995, p. 555-586.

425. P. Spirtes, C. Glymour, and R. Scheines, Causation, Prediction, and Search, Cambridge, MA, MIT Press, 2001

426. Lawrence Sklar, Idealization and Explanation: A Case Study from Statistical Mechanics, in: $[484$, p. 258-270].

427. Lawrence Sklar, Physics and Chance. Philosophical Issues in the Foundations of Statistical Mechanics, Cambridge University Press, 1993.

428. D.P. Skvortsov and V.B. Shetman, Maximal Kripke-Type Semantics for Modal and Superintuitionistic Predicate Logics, Annals of Pure and Applied Logic, 63, 1993, p. 69-101.

429. P. Smolensky, Connectionism, constituency and the language of thought, in: [305, p. 180222].

430. Michael B. Smyth, Topology, in: [485].

431. W. Spohn et al., Existence and Explanation, Kluwer Academic Publishers, Dordrecht, 1991.

432. Edward P: Stabler, The Logical Approach to Syntax. Foundation, Specification and Implementation of Theories of Government and Binding, ACL-MIT Press Series in Natural Language Processing, MIT Press, Cambridge MA, 1992.

433. Edward P. Stabler, Derivational Minimalism, in: [379].

434. Wolfgang Stegmüller, The Structuralist View of Scientific Theories, Springer, 1979.

435. Keith E. Stenning and Michiel van Lambalgen, Semantics as a foundation for psychology: a case study of Wason's selection task, Journal of Logic, Language and Information, 10, 2001, p. 273-317.

436. Wolfgang Sternefeld, Syntaktische Grenzen. Chomsky's Barrierentheorie und ihre Weiterentwicklungen, Westdeutscher Verlag, Opladen, 1991.

437. S. Stich and T. Warfield, Mental Representation: a Reader, Oxford, Blackwell, 1994. 
438. F. Suppe, The semantic conception of theories and scientific realism, University of Illinois Press, 1988.

439. P. Suppes, What is a scientific theory?, in: [334].

440. N. Suzuki, Algebraic Kripke Sheaf Semantics for Non-Classical Predicate Logics, Studia Logica, 63:3, 1999, p. 387-416.

441. E. Stenius, Principles of a logic of normative systems. Acta Philosophica Fennica 16, 1963, p. 247-260.

442. William W. Tait, Finitism, Journal of Philosophy, 1978, 1981, p. 524-546.

443. Gaisi Takeuti, Proof Theory, 2nd ed., Studies in Logic and Foundations of Mathematics, Elsevier, Amsterdam, 1987.

444. K. Tanaka and T. Yamazaki, Arithmetical functionals and Weak König's Lemma.

445. A. Tarksi, The concept of truth in formalized languages, 1935, reprinted in: [446], p 152278.

446. A. Tarski, Logic, Semantics, Metamathematics, Second edition edited and introduced by J. Corcoran, Hackett, 1983.

447. J.W. Thatcher, Characterizing Derivation Trees of Context-Free Grammars through a Generalization of Finite Automata Theory, J. Comput. System Science, 1, 1967, p. 317-322.

448. J.W. Thatcher and J.B. Wright, Generalized Finite Automata with an Application to a Decision Problem of Second Order Logic, Mathematical Systems Theory 2 (1968), p. 57 82.

449. J. W. Thatcher and J. B. Wright, Generalized finite automata theory with an application to a decision problem of second-order logic, Mathematical Systems Theory, 2, 1968, p, 57-81.

450. R. Thomason, A note on syntactical treatments of modality, Synthese, 44, 1980, p. 391395.

451. H.-J. Tiede, Lambek Calculus Proofs and Tree Automata, in: [332].

452. H.-J. Tiede, Proof Tree Automata, in: [25].

453. H.-J. Tiede, Deductive Systems and Grammars: Proofs as Grammatical Structures, PhD thesis, Indiana University, 1999.

454. S. Toyoda, Y. Kakuda, S. Kitamura and T. Kotani, Interpreting Abstract Design Theory by simple filter circuit, Artificial Intelligence in Engineering, to appear.

455. A.S. Troelstra, Lectures on linear logic, CSLI Publications, 1992.

456. A.S. Troelstra and H. Schwichtenberg, Basic Proof Theory, Cambridge University Press, 2000.

457. M. Tumita (ed.), Generalized LR Parsing, Kluwer, 1991.

458. C. Umbach, et al. (eds.), Perspektive in Sprache und Raum, Studien zur Kognitionswissenschaft, Wiesbaden, Deutscher Universitaetsverlag, 1996

459. A. Urquhart, The Complexity of Decision Procedures in Relevance Logic, in: [118].

460. A. Urquhart, The Complexity of Propositional Proofs, Bulletin of Symbolic Logic, 1:4, 1995, p. 425-467.

461. Steven Vickers, Topology via Logic, Cambridge University Press, 1989.

462. Steven Vickers, Topology via constructive logic, in: [177].

463. Albert Visser, Semantics and the Liar Paradox, in: [154, p.617-706].

464. Heinrich Wansing, The Logic of Information Structures, Springer, 1993.

465. O.Watari, K. Nakatogawa, and T. Ueno, Normalization theorems for substructural logics in Gentzen-style natural deduction, Bulletin of Symbolic Logic, 6:3, 2000, p. 390-391.

466. Gert Webelhut, Government and Binding Theory and the Minimalist Program, Blackwell, 1995.

467. Markus Werning, How to solve the problem of compositionality by oscillatory network, in: [331, 1094-1099].

468. Markus Werning, A. Maye, personal correspondance 2001 
469. D. Westerstahl, On the Compositionality of Idioms, in: [26].

470. Dag Westerstahl, Quantifiers in formal and natural languages, in: [154, p. 1-131].

471. A. Wightman, Statistical Mechanics and Ergodic Theory, in: [110, p. 11-16].

472. A. Wightman, Regular and Chaotic Motions in Dynamical Systems, in: [473]

473. G. Velo and A. Wightman (eds.), Regular and Chaotic Motions in Dynamical Systems, Plenum Press, 1985.

474. T. Williamson, Knowledge and its Limits, Oxford University Press, 2000.

475. S. Winfrid, Inference and Meaning, Mind, 62, 1953, p. 313-338; reprinted in: Pure Pragmatics and Possible Worlds, Ridgeview, Atascadero CA, p. 261-286.

476. Terry Winograd, Language as a Cognitive Process: Syntax, Addison-Wesley, 1983.

477. Frank Wolter et. al., Advances in Modal Logic, Volume 3, ??? 2001 [Studies in Logic, Language and Information]

478. H. Yoshikawa, General design theory and a CAD system, in: [402], p. 35-57.

479. Edward N. Zalta, Logical and Analytic Truth that are Not Necessary, Journal of Philosophical Logic, 85, 1988, p. 57-74.

480. G. Zoubek, B. Lauth, Zur Rekonstruktion des Bohrschen Forschungsprogramms I, Erkenntnis, 37, 1992, p. 223 - 247.

481. G. Zoubek, B. Lauth, Zur Rekonstruktion des Bohrschen Forschungsprogramms II, Erkenntnis, 37, 1992, p. 249 - 273.

482. Models for Modalities. Selected Essays, D. Reidel Publishing Company, Dordrecht, 1969.

483. Models and Metaphors, Cornell University Press, 1965.

484. Minnesota Studies in Philosophy, vol. XVII: Philosophy of Science, 1993.

485. S. Abramsky, Dov M. Gabbay, and T.S.E. Maibaum, Handbook of Logic in Computer Science, Vol. 1: Background: Mathematical Structures, Oxford University Press, 1992.

486. S. Abramsky, Dov M. Gabbay, and T.S.E. Maibaum, Handbook of Logic in Computer Science, Vol. 3: Semantic Structures, Oxford University Press, 1994.

487. Computer Science Logic, 14th Annual Conference of the EACSL, LNCS 1862, 2000. Springer.

488. Proc. 12th Amsterdam Colloquium, 1999.

489. Proc. Joint Conference on Formal Grammar and Mathematics of Language, 2001.

490. Ontological Relativity and Other Essays. Columbia University Press, New York, 1969.

491. Supervenience and Mind, Cambridge University Press, Cambridge MA, 1993.

492. Explaining Behavior, MIT Press, Cambridge MA, 1988. 